\title{
CARACTERÍSTICAS MIOFUNCIONAIS \\ OROFACIAIS E VOCAIS DAS CRIANÇAS DO \\ MUNICÍPIO DE MONTE NEGROIRO
}

\section{LUCIANA BIRAL MENDES MERIGHI}

Dissertação apresentada à Faculdade

de Odontologia de Bauru, da

Universidade de São Paulo, como parte dos requisitos para obtenção do título de Mestre em Fonoaudiologia. 


\section{CARACTERÍSTICAS MIOFUNCIONAIS \\ OROFACIAIS E VOCAIS DAS CRIANÇAS DO \\ MUNICÍPIO DE MONTE NEGRO/RO}

\section{LUCIANA BIRAL MENDES MERIGHI}

Dissertação apresentada à Faculdade

de Odontologia de Bauru, da

Universidade de São Paulo, como parte dos requisitos para obtenção do título de Mestre em Fonoaudiologia.

Orientadora: Profa. Dr. ${ }^{a}$ Katia Flores Genaro 
Merighi, Luciana Biral Mendes

M543c Características miofuncionais orofaciais e vocais das crianças do município de Monte Negro/RO Luciana Biral Mendes Merighi. -- Bauru, 2006. xiii, 91p. : il. ; $30 \mathrm{~cm}$.

Dissertação (Mestrado) -- Faculdade de Odontologia de Bauru . Universidade de São Paulo.

Orientadora: Profa ${ }^{a}$ Dra . Katia Flores Genaro

Descritores: respiração, mastigação, deglutição, fala, voz.

Autorizo, exclusivamente pra fins acadêmicos e científicos, a reprodução total ou parcial desta dissertação, por processo fotocopiadores e/ou meios eletrônicos.

Assinatura do autor:

Data:

Comitê de Ética da FOB-USP

Protocolo n. ${ }^{0121 / 2005}$

Data: 30/11/2005 


\section{LUCIANA BIRAL MENDES MERIGHI}

23 de março de 1972

Bauru - SP

1991-1994

1995-1996

1997

1997-1998

2001-2002

1998

2003

2004

2005-2006
Nascimento

Graduação em Fonoaudiologia - Universidade do Sagrado Coração - Bauru/SP

Fonoaudióloga da APAE Birigui - Vínculo celetista

Aperfeiçoamento na Reabilitação de Lesões Lábio Palatais - Hospital de Reabilitação de Anomalias Craniofaciais/USP

Fonoaudióloga do Lar e Escola Rafael Maurício Vínculo celetista

Fonoaudióloga da APAE Jundiaí - Vínculo celetista

Aperfeiçoamento na Reabilitação das Deficiências Auditivas - Hospital de Reabilitação de Anomalias Craniofaciais/USP

Aperfeiçoamento em Fonoaudiologia Aplicada à Clínica Odontológica - Faculdade de Odontologia de Bauru/USP

Prática Profissionalizante - Motricidade Oral e Voz FOB/USP

Mestrado em Fonoaudiologia - Faculdade de Odontologia de Bauru/USP 


\section{DEDICATÓRIA}

“....Ainda que falasse a língua dos homens, e falasse a língua dos anjos, sem amor eu nada seria..."

Vocês são meus amores - meu marido Marcio, às minhas filhas Thaís e Bruna. 


\section{Agradecimentos}

Agradeço, em primeiro lugar, a Deus, pela oportunidade de vivenciar este momento.

Obrigada à minha família e aos meus amigos, que me apoiaram desde o início, a quem, ainda, peço desculpas pela minha ausência.

Especial menção merece minha orientadora, Prof ${ }^{a}$. Dr ${ }^{\underline{a}}$ Kátia Genaro Flores, a quem agradeço pelo carinho, paciência e profissionalismo, pela competência e pelo meu engrandecimento profissional.

À Prof ${ }^{a}$. Dr ${ }^{a}$ Giédre Berretitin-Félix e a Dr ${ }^{\underline{a}}$ Ana Claudia Martins Sampaio que me ajudaram orientando e promovendo grande enriquecimento ao trabalho com suas sugestões.

Aos colegas que viajaram comigo para Rondônia, especialmente aos meus "braços direito e esquerdo" na coleta dos dados Amanda e Marcela, aluna do $4^{\circ}$ ano, pela ajuda e companheirismo incomensurável.

Às crianças, à Diretora e à Vice-diretora da escola Mato Grosso, de Monte Negro, sem as quais não seria possível a realização deste trabalho.

A toda a população de Monte Negro, pela acolhida, pelo respeito e pela importância que dispensa ao nosso trabalho.

Aos professores do Mestrado, pelos conhecimentos transmitidos, em especial ao Prof. Dr Lauris e Prof. Dr. José Roberto, às Prof ${ }^{a}$. Dr ${ }^{a}$ Cidinha, Alcione, Lídia, Dionísia, Luciana e Magali.

As fonoaudiólogas especialistas em voz, Daniela Modolo, Fabiane Figueiredo e Simone Bastazine, às quais desempenharam papel importante como Juízes das vozes das crianças e a Cristiane, que facilitou o trabalho de voz.

Ao Douglas do Projeto Florida que sempre com muita simpatia, auxiliou na organização das imagens coletadas.

Ao Augusto, que me auxiliou na tradução e compreensão dos textos.

A todos os funcionários da USP que, direta ou indiretamente, contribuíram para a concretização deste estudo, merecendo menção, pela infinita ajuda, ao pessoal da Clínica de Fonoaudiologia, os colegas Wellington e Karina do departamento, Rita, César, Ademir, Cibele, Aninha da biblioteca.

Às minhas todas amigas de Mestrado pelos momentos agradáveis, difíceis e divertidos que passamos juntas e pela amizade consolidada, em especial a Daniela, Izabel, Simone, Maria Cecília, Daphine e Mariana, que por vezes pedi socorro!!!!!

Obrigada a todos. Muito obrigada!!!! 


\section{SUMÁRIO}

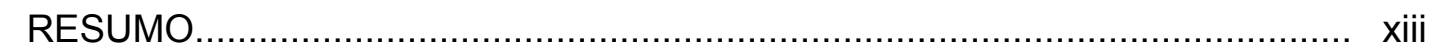

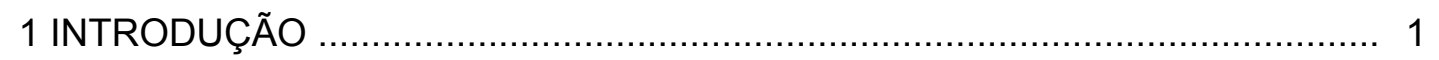

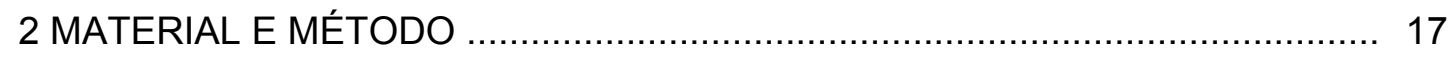

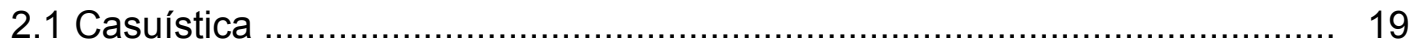

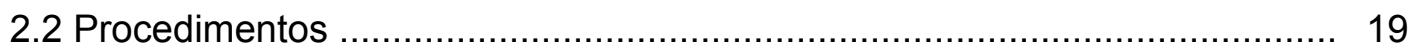

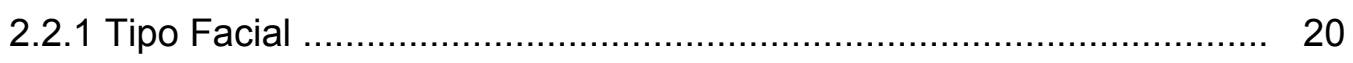

2.2.2 Relação Dentária .................................................................... 20

2.2.3 Postura Habitual dos Lábios e da Língua ...................................... 21

2.2.4 Estado de Contração Muscular ......................................................... 21

2.2.5 Mobilidade e Motricidade ............................................................. 21

2.2.6 Respiração ............................................................................. 22

2.2.7 Mastigação ............................................................................... 23

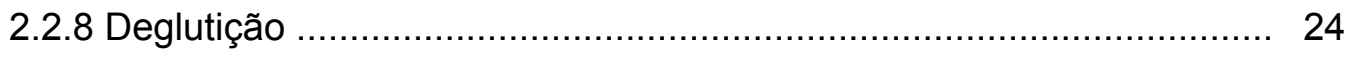

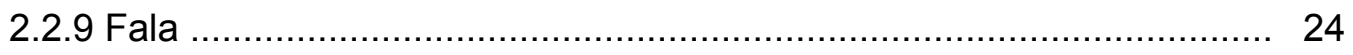

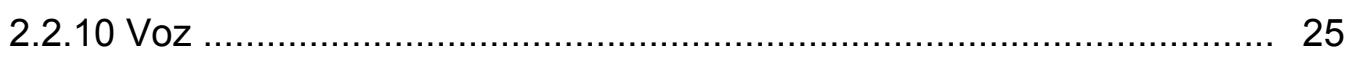

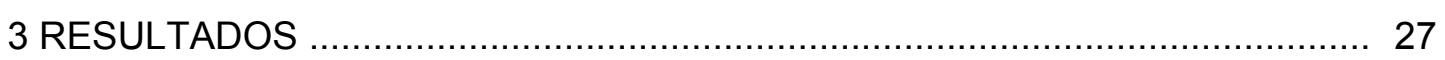

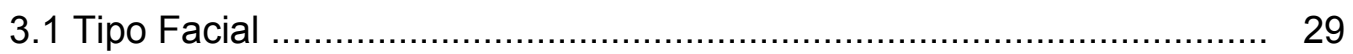

3.2 Relação Dentária ...................................................................... 29

3.3 Postura Habitual dos Lábios e da Língua ......................................... 31

3.4 Estado de Contração Muscular .......................................................... 33

3.5 Mobilidade e Motricidade ....................................................... 35

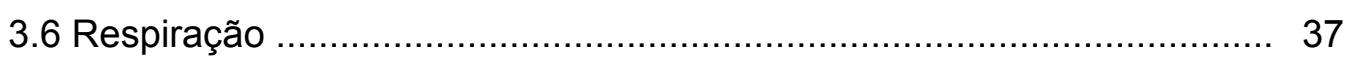

3.7 Mastigação …..................................................................... 38

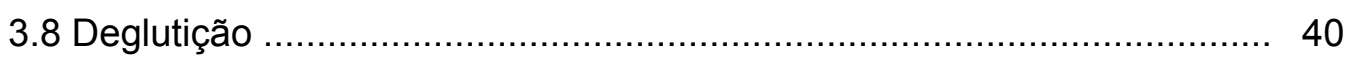

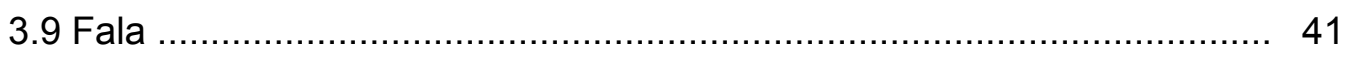

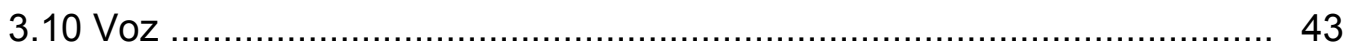

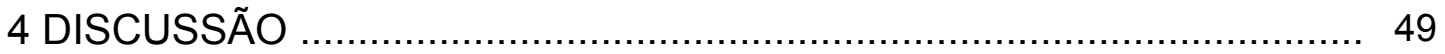

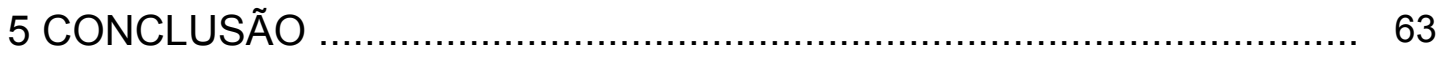

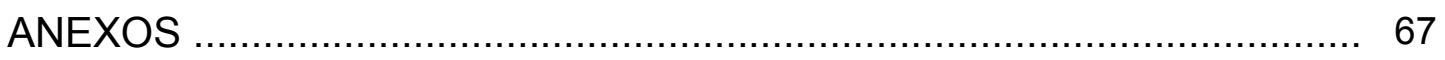

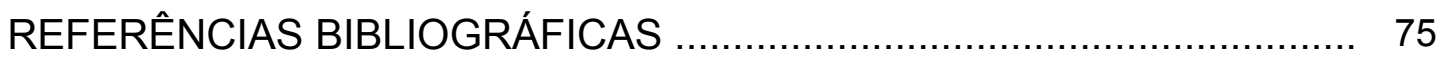

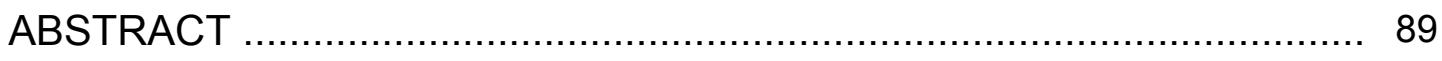




\section{Resumo}

É de grande importância à realização adequada das funções orais - as quais influenciam e sofrem influência dos aspectos morfológicos e miofuncionais orofaciais - para possibilitar o equilíbrio e desenvolvimento do complexo craniofacial. Assim, distúrbios miofuncionais orais podem interferir de forma negativa no desenvolvimento craniofacial, refletindo se também no desenvolvimento psicossocial da criança. O trabalho visou caracterizar os aspectos miofuncionais orofaciais e vocais crianças do município de Monte Negro/RO. Respeitando-se os aspectos éticos, dois grupos de escolares do município de Monte Negro/RO, de ambos os gêneros, foram formados de acordo com a faixa etária: grupo I (GI) composto por 47 crianças entre 6 e 8 anos e grupo II (GII) formado por 36 crianças entre 9 e 11 anos. A partir da avaliação miofuncional orofacial convencional, as crianças foram avaliadas quanto aos aspectos estruturas como: tipo facial e relação dentária, postura habitual dos lábios e da língua; estado de contração muscular dos lábios, língua, bochechas, masseteres e mentual; mobilidade e motricidade dos lábios, língua, mandíbula e véu palatino; além das funções de respiração, mastigação, deglutição, fala e voz. Foram utilizadas filmagens e gravação em MD para a coleta dos dados, e posterior análise, necessários à pesquisa. Os resultados demonstram para os dois grupos, alterações nas relações dentárias, bem como nos aspectos miofuncionais orofaciais no que se refere ao estado de contração muscular, mobilidade e motricidade, bem como para as funções respiratórias, especificamente quanto ao modo; a função mastigatória, principalmente, quanto a formação do bolo alimentar, conseqüentemente, alterações quanto a deglutição, e no que se refere a fala e a voz, as alterações apresentaram -se em menor porcentagem. Portanto a promoção de ações que viabilizem o trabalho de adequação das funções orofaciais e da voz, bem como o desenvolvimento de programas de prevenção na área de Motricidade Oral, tornam-se essenciais para o desenvolvimento das crianças do município de Monte Negro/RO.

Palavras-chave: sistema estomatognático, respiração, mastigação, deglutição, fala, criança e voz. 
1 Introducão 



\section{Introdução}

O ser humano é participante ativo em seu desenvolvimento e busca manter um estado de equilíbrio com o ambiente, passando por vários processos ao longo de sua vida (FAW, 1981). Além das características genéticas reguladoras, estruturas e sistemas sofrem influências do meio ambiente, favorecendo ou modificando seu crescimento e desenvolvimento, caracterizando-o como um ser biopsicossocial, devido à intrínseca relação entre corpo, mente e ambiente social (LEAVELL; CLARK 1976).

As estruturas craniofaciais desenvolvem-se a partir de fatores internos e externos, por meio de três mecanismos: aumento do volume ósseo, remodelação, e deslocamento das estruturas ósseas, sendo os músculos fundamentais para o crescimento, uma vez que promovem os processos de aposições e reabsorções, alterando toda estrutura óssea em diferentes proporções (PROFFIT, 2002, KÖHLER, 2000).

$O$ processo de crescimento facial requer inter-relações morfogênicas íntimas entre as partes dos tecidos moles e duros que estão em crescimento e desenvolvimento, cuja meta é o estado de equilíbrio funcional e estrutural complexo (LINDEN, 1990, ENLOW, 1998). Assim, estruturas passivas (arcos osteo-dentários) e estruturas dinâmicas (unidade neuromuscular), que compõem o sistema estomatognático, são responsáveis pelo desempenho de funções controladas pelo sistema nervoso que, trabalhando de forma equilibrada, contribuem para o funcionamento harmônico da face e para o desenvolvimento craniofacial (DOUGLAS, 2002).

Portanto, a função e a morfologia estão intimamente relacionadas, requerendo uma organização harmônica das estruturas para a saúde e equilíbrio do sistema estomatognático (KÖHLER, 2000, FELíCIO, 2004).

Por meio de análise da morfologia orofacial, observa-se a importância que o equilíbrio dentofacial e a harmonia dos traços faciais (tecido mole), desempenham na aparência do indivíduo na sociedade (SUGUINO, 1996). Pode-se, assim, analisar a proporção dos terços faciais e os tipos de face, cujas características musculares e funcionais são peculiares. (CAPELOZZA, 1995, BIANCHINI, 2001). No tipo facial mesocefálico (médio) os terços da face são equilibrados e apresentam boa distribuição dos espaços funcionais e 
acomodação da musculatura, não sendo necessárias adaptações funcionais. O braquicefálico (curto) caracteriza-se por padrão de crescimento horizontal, sendo o terço inferior reduzido e a musculatura potente, especialmente dos masseteres. Já, o predomínio do crescimento facial vertical caracteriza o tipo facial dolicefálico (longo), com o terço inferior aumentado, palato profundo e estreitado, musculatura débil e estirada (ENLOW, 1998, PROFFIT, 2002).

Existe uma complexa inter-relação entre o crescimento craniofacial e o desenvolvimento da dentição, bem como de que maneira são exercidas as funções na região oral, determinando aspectos relevantes durante a infância. Esse desenvolvimento é gradativo e contempla o primeiro período transitório, o período intertransitório e o segundo período transitório, ocorrendo desde a formação completa da dentição decídua, por volta de 2,5 anos de idade, até a dentição permanente, próximo dos 13 anos de idade, à exceção dos terceiros molares (LINDEN, 1990).

$\mathrm{Na}$ dentadura mista ocorrem mudanças na inclinação dos dentes incisivos (lábio-lingual e mésio-distal) devido ao processo de transição da dentição decídua para a permanente (FIGUEIREDO; PARRA, 2002). Nesta época da dentadura mista, os incisivos superiores apresentam-se protruídos, com possível trespasse horizontal aumentado e convergência das raízes; ocorre espaçamento dos incisivos superiores e dos incisivos laterais inferiores, em alguns casos, e a irrupção dos incisivos centrais superiores pode ser em posição lingual em relação aos inferiores (FARIA, 2005). Com o crescimento e desenvolvimento, as inclinações mésio-distal e lábio-lingual se modificam e as raízes tendem a divergir (COENRAZ; MOORREES, 1965). Várias mudanças ocorrem na posição dos incisivos, estes ficam mais vestibularizados em relação às bases ósseas e isto ocorre, em parte, como resultado do crescimento e desenvolvimento da maxila e mandíbula, quando há aumento favorável na porção posterior, possibilitando a irrupção dos molares, e do processo alveolar durante a dentadura mista e dentição permanente (FIGUEIREDO; PARRA, 2002, FARIA, 2005).

Deste modo, aos 6 anos de idade, inicia-se a irrupção do primeiro molar permanente, aos 7 anos as trocas dos incisivos centrais e, próximo aos 8 anos, a dos incisivos laterais; entre 9 e 10 anos, ocorre a troca do molares decíduos 
pelos primeiros e segundos pré-molares e, por volta dos 11 anos, se dá a irrupção do segundo molar (SOUZA-FREITAS, 1991, NEVES, 2003, CANÇADO, 2003). Neste período, as estruturas ósseas confrontam com mudanças na cavidade intra-oral, sofrendo pressões dos lábios, da língua e das bochechas, na postura de repouso e durante realização das funções orais (PONTES et al., 1999). Portanto, ocorrem ajustes e alterações dessas estruturas na região anterior, durante as trocas dos incisivos e, na região posterior, com a troca dos molares (LINDEN, 1990).

Dentre as diferentes funções orais como a sucção, a mastigação, a deglutição, a respiração e a fala ressaltam-se a postura habitual de repouso dos lábios e língua, como uma outra função e de papel importância no desenvolvimento e crescimento craniofacial (JUNQUEIRA, 1997, CAMPIOTTO, 1998, BORGHI; ROLDÂO; MARIOTTO, 2003).

A sucção se desenvolve, inicialmente, como um ato reflexo, por volta da $20^{\mathrm{a}}$ semana de vida intra-uterina até a $32^{\mathrm{a}}$ semana de gestação e, por volta do $4^{\circ}$ mês após o nascimento, passa a ter controle voluntário (MACMULLEN; DULSKI, 2000, NEIVA, 2003). Aos seis meses de idade, ocorre um amadurecimento das funções orais, com aumento da pressão intra-oral e mudança no padrão de movimento da língua, sendo essa fase considerada crítica para o desenvolvimento da habilidade oral, permitindo a introdução de alimento mais espesso e, consequentemente, os estímulos que promovem o crescimento ósseo e mudanças na musculatura orofacial, favorecendo o equilíbrio dessas estruturas, necessários para a harmonia facial como: oclusão normal e desenvolvimento dos órgãos fonoarticulatórios (STEVENSON; ALLAIRE, 1991, ANDRADE; GULLO, 1993, BISHARA, et al., 2006, NETTO, 2003).

A partir desse processo, a retrusão fisiológica da mandíbula, observada ao nascimento, vai sendo corrigida por meio dos movimentos de sucção, promovendo o seu correto posicionamento e a instalação da oclusão decídua normal, bem como o início da remodelação das articulações temporomandibulares que, nesta fase, são planas (KÖHLER, 2000, GRANVILLE-GARCIA et al., 2000, FELÍCIO, 2004). Além disso, a função de sucção, quando realizada a partir do aleitamento materno, também apresenta 
vantagens devido ao valor nutritivo e emocional, necessários para 0 desenvolvimento do bebê (ANDRADE; GARCIA, 1998, DOUGLAS, 2002, NEIVA, 2003).

A mastigação é uma outra função importante, sendo considerada um ato fisiológico e complexo, que envolve atividades neuromusculares e digestórias. Sua evolução é gradativa e depende de padrões de crescimento, desenvolvimento e amadurecimento do complexo craniofacial, sistema nervoso e das guias oclusais (MARCHESAN, 1999, YAMASHITA; HATCH; RUGH 1999, VIEIRA; IÓRIO; ASSENCIO-FERREIRA, 2003, DUARTE, 2003).

A irrupção dos dentes decíduos, entre as idades de 6 a 24 meses, facilita o desenvolvimento da mastigação, com aumento do impulso sensorial e formação de uma superfície mastigatória; gradualmente, os movimentos de rotação da mandíbula e maior lateralização da língua contribuem para o efeito de manuseamento, trituração e moagem dos alimentos (SHEPPARD; MYSAK, 1984, NETTO, 2003, SANTOS et al., 2006). As ações musculares para a degradação mecânica dos alimentos, por meio dos movimentos de abaixamento, elevação, lateralização, protrusão e retrusão mandibular, promovem a remodelação morfofuncional das articulações temporomandibulares, que ao nascimento são planas (BIANCHINI, 1998, FELÍCIO, 2004).

Inicialmente, durante a fase de dentição decídua, o padrão mastigatório realizado é o de amassamento, que vai sendo substituído, gradativamente, pelo padrão bilateral alternado até por volta dos 5 anos de idade (VIEIRA; IÓRIO; ASSENCIO-FERREIRA, 2003, FREITAS; GREGIO; PEREIRA, 2004).

Por volta dos 6 anos, a criança apresenta um aumento da eficiência mastigatória e, após os 16 anos, alcança níveis próximos aos dos adultos (NETTO, 2003, TORO, 2006). Portanto, a mastigação atua como estímulo para a irrupção dentária e aumento das dimensões dos arcos osteodentários, sendo também uma forma capaz de produzir o desenvolvimento antero-posterior e transversal da maxila e mandíbula (BIANCHINI, 1998, DOUGLAS, 2002).

Diferindo-se da mastigação, por ser uma função inata e inicialmente reflexa, a deglutição resulta da ação sincrônica e coordenada de vários grupos musculares da cavidade oral, faringe e esôfago; sendo que os movimentos 
realizados por esses grupos musculares são modulados por comandos do sistema nervoso central, integrados com estímulos sensoriais e ações motoras periféricas (Douglas, 2002).

De acordo com o amadurecimento do sistema estomatognático têm-se dois padrões de deglutição: o infantil ou visceral e o padrão maduro ou adulto (MOYERS, 1991, KRAMER, 1985, GRANVILLE-GARCIA et al., 2000, NETTO, 2003). O padrão infantil caracteriza-se pelo posicionamento anteriorizado da língua entre os rebordos alveolares, participação da musculatura orbicular, e de bucinador (BROWN, 1996, GRANVILLE-GARCIA et al., 2000, NETTO, 2003). A transição da deglutição infantil para a madura ocorre em vários meses, a partir da maturação dos elementos neuromusculares, à medida que a propriocepção causa modificações funcionais e posturais na língua (NETTO, 2003).

Estabelecido o padrão maduro por volta dos 4 anos, observam-se os dentes em oclusão, o ápice da língua mantido contra o palato, acima e atrás dos incisivos superiores, pouca participação da musculatura orbicular, elevação e anteriorização da laringe e do osso hióide, além da estabilização da mandíbula (KRAMER, 1985, MOYERS, 1991, MARCHESAN, 1999, FELÍCIO, 2004).

Para auxiliar no diagnóstico da deglutição de forma mais objetiva, estudos utilizando técnicas de ultra-sonografia e videofluoroscopia vêm sendo utilizados para investigar a duração dos movimentos da língua, possibilitando diferenciar o padrão de deglutição maduro do infantil, sendo destacado o músculo genioglosso como referencial para essa diferenciação (KIKYO; SAITO; ISHIKAWA, 1999. PENG et al., 2003, PENG et al., 2004, KAWAMURA et al., 2003).

Em sincronia com a deglutição, a respiração é considerada vital à existência do homem, além de ser fundamental para o desenvolvimento e manutenção da saúde das estruturas orofaciais (DOUGLAS, 2002). Pode-se considerar a respiração quanto ao modo, referindo-se à via pela qual acontecem a inspiração e a expiração - oral ou nasal, e quanto ao tipo, que se relaciona ao uso dos pulmões para a realização da respiração - expansão pulmonar. No recém-nascido, a respiração é essencialmente nasal devido às 
estruturas anatômica, pois o tamanho da mandíbula torna a cavidade oral pequena em relação ao tamanho da língua; essa relação se mantém até os 3 ou 4 meses de vida, quando a criança tem a possibilidade de respirar pela boca (KRAMER, 1985, MARCHESAN, 1999).

Em condições de repouso, o modo respiratório deve ser exclusivamente por via nasal, pois o nariz possui funções como filtrar, umidificar e aquecer o ar a ser inalado; os lábios mantêm-se selados, a mandíbula encontra-se em repouso e a língua em contato com o palato, permitindo a ação de forças de expansão na maxila, que se equilibra com as forças restritivas do músculo bucinador e a pressão aérea da cavidade nasal (DOUGLAS, 2002, KÖHLER, 2000, DUCAT et al., 2001).

Estas são condições favoráveis para que as informações sensoriais provenientes da mucosa oral, dos músculos levantadores da mandíbula, cervicais, faciais e linguais, bem como das articulações temporomandibulares contribuam de modo adequado, propiciando respostas motoras dentro dos padrões de normalidade, garantido equilíbrio entre sistema estomatognático, postura corporal e da cabeça (GOMES, 1999, KRAKAUER, 2001, AMANTĖA et al., 2004).

A respiração caracteriza-se pela inspiração (força ativa), com a contração dos músculos intercostais e diafragma, e pela expiração (passiva), quando o diafragma relaxa, ocorrendo retração elástica dos pulmões e da caixa torácica, o que provoca a expulsão do ar armazenado (ZEMLIN, 2002). Devido à variação do tipo respiratório, pode se encontrar desde protrusão considerável da parede abdominal a cada inspiração, até expansão lateral do tórax, com leve protrusão da parede abdominal; assim são descrito os tipos: diafragmático-abdominal ou completo, abdominal ou inferior, torácico ou médio e clavicular ou superior, sendo este último encontrado com menor freqüência e resultando em tensão excessiva na faringe, e suprimento impróprio do ar (BEHLAU et al., 2001, LE HUCHE; ALLALI, 2005).

Com o crescimento e a maturação, a respiração torna-se semelhante a de um adulto, sendo que o desenvolvimento total dos pulmões acontece por volta dos 8 anos (ZEMLIN, 2002). No primeiro ano de vida, ocorrem mudanças na forma e complacência pulmonar, aumentando a participação do movimento 
torácico, tornando-se similar a de um adolescente (HERSHENSON et al., 1990, PAPASTAMELOS et al., 1995).

O movimento toracoabdominal e a capacidade vital foram estudados por VERCHAKELEN; DEMEDTS, 1995, que consideraram fatores como gênero, idade e posição do corpo (em pé, sentado e supino). O coeficiente do volume/movimento obtido durante a respiração, em repouso, foi duas vezes maior para o tórax do que para o abdômen, com diferença estatisticamente significativa apenas para a posição supino, demonstrando aumento do volume e movimento na região abdominal. Estes achados são similares aos dos estudos de MAYER et al., 2003, que ressaltaram a dependência da posição corporal, alterando medidas na mecânica respiratória.

Para TOBIN et al., 1983a e TOBIN et al., 1983b, a interpretação da relação volume pulmonar, tempo da mecânica respiratória (inspiração e expiração) e as contribuições do compartimento torácico e abdominal durante o padrão respiratório, têm sido utilizadas na prática clínica como informações quantitativas, auxiliando no diagnóstico. Os resultados demonstraram movimentos simétricos (bilateralmente), não sendo observadas mudanças estatisticamente significativas, em relação à idade e ao gênero, sendo a média do tipo respiratório maior para o compartimento abdominal durante o repouso, embora para alguns pacientes o predomínio tenha sido torácico, corroborando com o estudo de RAGNARSDOTTIR; KRISTINSDOTTIR, 2000.

Além do papel vital da respiração, esta também tem importância fundamental na produção da fala e da voz, visto que as mesmas são realizadas a partir da modificação da corrente aérea expiratória e das ondas acústicas (DOUGLAS, 2002, DUARTE, 2003, MARCHESAN, 2004).

A fala é uma das formas de expressão da linguagem e utiliza-se de órgão pertencente a outros sistemas, como o respiratório e o digestório, dependendo da movimentação de estruturas orofaciais, como lábios, véu palatino, dentes e língua (DOUGLAS, 2002, MARCHESAN, 2004). Ocorre, ainda, interação entre o sistema motor da fala e a formulação da linguagem, sendo o controle motor influenciado e também influenciando o desenvolvimento da linguagem, portanto não podem ser considerados separadamente (HAGE, 1999/2000, WERTZNER, 2001). 
Durante o processo de aquisição da fala, as crianças aprendem quais sons são usados na sua língua e de que maneira eles são organizados, assim adquirem o inventário fonético e as regras fonológicas de forma gradativa, considerando os fonemas, a sua distribuição e o tipo de estrutura silábica onde ocorrem (INGRAN 1976, STOEL-GRAMMON; DUNN 1985, ELBERT; GIERUT, 1991, PORTER; HODSON, 2001).

A produção da fala tem inicio por volta dos seis meses de vida (período pré-lingüistico), quando os bebês produzem o balbucio, que pode ser representado pelos sons das vogais (NOBRE; DE-VITTO, 2005). Entre um ano e um ano e seis meses surgem as primeiras palavras, usadas isoladamente e compostas por consoantes simples $(/ \mathrm{p} /, / \mathrm{m} /$, e/ $\mathrm{k} /)$, vogais e semivogais; e a partir desta fase, ocorrem os processos de simplificações das regras fonológicas, como omissões, substituições, entre outros, na tentativa de aproximar a sua fala a do adulto, para organizar, assim, as regras fonológicas. (DINNSEN; BARLOW, 1998). Essas simplificações podem ocorrer devido à imaturidade articulatória, perceptual e do sistema nervoso (INGRAN, 1976). Um aumento considerável do inventário fonético e maior expansão do vocabulário ocorre após um ano e seis meses de idade, que se finaliza aos 4 anos com a eliminação da maioria dos processos de simplificação da fala utilizados, apresentando a aquisição da maioria dos sons da língua e do sistema fonológico de contrastes (ACOSTA, 2003).

Dos 4 aos 7 anos, surgem os sons mais complexos, como arquifonemas e encontros consonantais, aumentando a inteligibilidade da fala e proporcionando estabilidade ao sistema fonológico, o que favorece a comunicação e o convívio social (LAMPRECHT et al., 2004, WERTZNER, 2001). Geralmente, a partir desta idade, a criança começa a fazer relações entre o código oral e escrito, passando a discriminar os fonemas dentro das palavras e a separá-los, assim, por meio da habilidade de análise, síntese, rima e aliteração, desenvolvem a consciência fonológica (JAGER; ADAMS et al., 2006).

Como parte do complexo processo de aquisição da fala, a voz representa e acompanha o desenvolvimento do indivíduo do ponto de vista físico, psicológico e social (MELO et al., 2001). 
Após o nascimento, a laringe infantil apresenta diferenças anatômicas e fisiológicas, diferindo-a da laringe adulta. Algumas dessas diferenças são demonstradas quanto à flexibilidade das cartilagens, nos ligamentos mais frouxos, tecidos epiteliais das prega vocais mais densos, abundantes e vascularizados, menor extensão da porção vibrátil das pregas vocais e pobre qualidade vocal fonatória devido às características anatômicas e histológicas do trato vocal (BEHLAU et al., 2001, LE; HUCHE; ALLALI, 2005).

Assim, os parâmetros vocais infantis, também diferem do adulto, sendo descritos como: freqüência fundamental acima de $250 \mathrm{~Hz}$, pitch agudo, intensidade vocal de moderada para elevada, tendência à elevação do loudness, extensão e estabilidade vocais reduzidas, ataque vocal brusco, tipo respiratório superior, incoordenação pneumofonoarticulatória e tempos máximos de fonação abaixo de 12 segundos, além disso, a qualidade vocal esperada apresenta-se com pouca projeção. Podem ser observadas, ainda, leve nasalidade, rouquidão e soprosidade, uma vez que é comum a criança apresentar fenda glótica (BEHLAU et al., 2001, ROCKENBACH; FEIJÓ, 2000).

Nota-se, portanto, na infância, a importância do desempenho adequado das funções orofaciais, as quais são influenciadas e influenciam os aspectos morfológicos e funcionais do sistema estomatognático, contribuindo para o desenvolvimento do complexo craniofacial e psicossocial, além da qualidade na comunicação.

Alguns fatores podem interferir no desenvolvimento da criança como, perdas prematuras dos dentes decíduos, causadas por trauma, cáries, reabsorção prematura ou extração, levando a apinhamentos e, principalmente, migrações dos dentes vizinhos em direção ao espaço criado (LINDEN, 1990, BIANCHINI, 1998). A perda precoce dos dentes decíduos parece retardar a irrupção do sucessor, interferindo no desenvolvimento da dentição permanente (LINDEN, 1990).

A presença de hábitos orais deletérios é um outro fator desfavorável ao crescimento e desenvolvimento craniofacial, sendo que o grau de severidade do hábito de sucção depende de parâmetros como, duração, freqüência e intensidade (GRABER, 1974). Diante desses casos, poderão ser observadas alterações dentárias, na relação entre a maxila e a mandíbula, na função e 
posição dos lábios, entre outros aspectos. Assim, em decorrência de forças mecânicas inadequadas, haverá desequilíbrio nas ações musculares, atuando sobre as bases ósseas, dentes e funções estomatognáticas (JOSELL, 1995, HALE; KELLUM; BISHOP, 1998, CORRÊA, 1999, KÖHLER, 2000, FELÍCIO, 2004).

Os hábitos orais deletério podem levar a doença periodontal, como as placas bacterianas, agravando e contribuindo para resultados insatisfatórios no restabelecimento das funções orais (PONTES et al., 1999, BOTTERO, ANSANELLI; MOTTA 2005).

As pesquisas realizadas envolvendo hábitos orais deletérios, como a interposição da língua durante a deglutição, a sucção digital ou de chupeta, morder ou sugar os lábios, entre outros, demonstram forte correlação entre a etiologia da mordida aberta anterior, estreitamento da maxila, mordida cruzada posterior ou outras alterações da oclusão, comprometendo a morfologia e a função do sistema estomatognático (GUABA, 1998, GARRETTO, 2001, JORGE et al., 2002, CHENG et al., 2002, FUKUMITSU et al., 2003, MACIEL; LEITE, 2005, ANTONINI et al., 2005). A importância do diagnóstico correto e a interferência dos hábitos orais deletérios no desenvolvimento craniofacial para o sucesso do tratamento, foram referidas por MONGUILHOT et al., 2003, sendo necessária a atuação multidisciplinar para reabilitar ou minimizar as alterações morfológicas e miofuncionais orofaciais.

Outros aspectos que interferem no desenvolvimento craniofacial são, as alterações musculares ou dentofaciais e tipo de dieta alimentar. Dieta muito macia promove diminuição dos estímulos necessários para a manutenção da saúde dos músculos, articulações e periodonto, que normalmente são obtidos durante a mastigação de alimentos mais consistente (FELÍClO, 1999, SILVEIRA; GOLDENBERG, 2001, CATTONI, 2004). Adaptação à dor, a perda de dentes e as desarmonias oclusais podem promover alterações quanto ao tipo mastigatório, como o tipo unilateral, que estimula de forma desequilibrada as estruturas orofaciais, altera o crescimento e equilíbrio neuromuscular e causam assimetria da musculatura, prejuízo das funções estomatognáticas e disfunção das articulações temporomandibulares (PLANAS, 1988, LAINE et al., 1992, MANDETTA, 1994, BIANCHINI, 1998, DOUGLAS, 2002). 
CORRUCCINI; HENERSON; KAUL, 1995, ao compararem o tipo de alimentação dos jovens da zona rural e urbana, constataram melhor oclusão dentária nos jovens de ambiente rural, contrariamente aos de ambientes urbanos, os quais são mais susceptíveis às alterações oclusais, com menor força de mordida, justificada pela dieta macia. TAKADA; MIYAWAKI; TATSUTA, 1994, também relataram as diferenças entre a consistência dos alimentos, referindo que a dieta mais consistente pode promover um melhor e mais coordenado crescimento facial.

TOMÉ; MARCHIORI; PIMENTEL, 2000, investigaram a dieta alimentar de respiradores orais e mostraram que estes desenvolvem menor força muscular e, conseqüentemente, problemas morfológicos e funcionais, além de prejuízos nutricionais, encontrando-se desde indivíduos muito magros até obesos.

Estudos envolvendo pequenos mamíferos sustentam a hipótese de que, mudanças nas técnicas de preparação e industrialização dos alimentos conduziram ao crescimento facial diminuído nos arcos mandibulares e maxilares destes, o que justifica as mudanças no desenvolvimento craniofacial em populações humanas com o passar dos anos (LIEBERMAN, 2004).

Em continuidade a função mastigatória tem-se a deglutição e, portanto, quando a mastigação está alterada, espera-se também alteração na fase oral desta função. Além disso, na presença de alteração estrutural da cavidade oral, como nos casos de deformidade dentofacial, espera-se desvios do padrão normal da deglutição, sendo esta considerada uma adaptação (CATTONI, 2004). Por outro lado, quando há movimentação inadequada da língua e dos lábios para a realização da deglutição, sem alteração estrutural, tem-se a deglutição atípica (MARCHESAN, 1998, PENG et al., 2004). Em geral, esta última decorre de alterações musculares, sensoriais e funcionais relacionadas ao tônus, mobilidade e sensibilidade dos órgãos orais e pode provocar má oclusão, como a mordida aberta anterior (BROWN, 1996, FELÍCIO, 1999, GARRETTO, 2001, FUJIKI, 2004, CATTONI, 2004, FRASER, 2006).

Coordenada com a deglutição, a respiração, se realizada por via oral, comprometerá todo o equilíbrio do sistema estomatognático, levando prejuízo no desenvolvimento craniofacial e também nas demais funções como a 
mastigação, a deglutição, a voz e a fala (MARCHESAN, 1998, TESSITORE, 2004, PAES et al., 2005, ANDRADE et al., 2005, LESSA et al., 2005). A causa mais freqüente da respiração oral é a obstrução nasal e/ou faríngea, podendo também, a flacidez dos músculos faciais e mastigatórios, levar à abertura da boca, causando a respiração oral funcional (MARCHESAN, 1998, DUARTE, 2003).

Indivíduos com respiração oral podem apresentar alteração de oclusão, hipofuncionalidade dos músculos mastigatórios e orofaciais e posicionamento incorreto da língua em repouso e durante as funções (JOSELL 1995, HALE; KELLUM; BISHOP, 1999, RODRIGUES et al., 2005). Nestes casos, a língua não exerce a função modeladora para ao crescimento transversal da maxila, justificando a atresia maxilar, que associada à diminuição da aeração nasal, contribuem para o aumento da profundidade do palato. Estes fatores causam diminuição da cavidade nasal e agravam a dificuldade da respiração por via nasal (JOSELL, 1995, SCHINESTSCK, 1996, SCHIEVANO; RONTANI; BÉRZIN, 1999, BIANCHINI, 2001). Além disso, PAES, 2005, enfatiza que o estado de desidratação da mucosa do trato vocal, imposto pela respiração oral, interfere no movimento vibratório das pregas vocais, gerando uma alteração na qualidade vocal.

Assim como as demais funções orofaciais, investigações relacionadas aos distúrbios da fala associados aos hábitos de sucção, a alterações oclusais, a alteração na deglutição e as desordens miofuncionais orofaciais vêm sendo realizadas por vários autores, cujos resultados confirmam a presença de dificuldades para coordenar ajustes motores finos, necessários para a articulação da fala (PENTEADO; ALMEIDA; LEITE, 1995, PEREIRA; SILVA; CECHELLA, 1998, TOMÉ et al., 1998, HALE; KELLUM; BISHOP, 1998, KHINDA; GREWAL, 1999, YASHIRO; TAKADA, 1999, SANTOS et al., 2000, PEREIRA et al., 2003, FELÍCIO, 2003b, FRIAS et al., 2004, PEREIRA et al., 2005).

Por meio da integridade estrutural ou funcional do sistema nervoso central, das estruturas sensório-motoras e funções auditivas, a criança adquire o domínio do sistema de uma língua (NOBRE; DE-VITTO, 2005). No entanto, a alteração da fala, envolvendo erros de produção, percepção ou organização 
interferem no rendimento escolar e/ou na comunicação social, caracterizando os transtornos fonológicos (WERTZNER, 2006). Estes podem afetar a produção e/ou representação mental dos sons da fala, provocando um grande impacto fonético, refletido na inabilidade de articular os sons da fala, bem como fonológico, afetando o modo pelo qual a informação sonora é armazenada, representada no léxico mental ou acessada e recuperada cognitivamente (GIERUT, 1998, WERTZNER, 2006).

Algumas produções acusticamente imprecisas dos sons da fala são consideradas, por PEREIRA et al., 2003, alterações fonéticas, onde o som é percebido de forma clara pelo falante, mas, por questões fisiológicas, não é capaz de reproduzi-lo adequadamente.

Técnicas objetivas como a cefalometria, a videofluroscopia e a eletropalatografia têm sido utilizadas para investigar as alterações das funções orofaciais, auxiliando não só no diagnóstico, como também na conduta mais adequada e na reabilitação e acompanhamento terapêutico (CAYLEY et al., 2000a, CAYLEY et al., 2000b, CHENG et al., 2002, FURKIN; BEHLAU; WECKX, 2003, BERTOLINI et al., 2003).

Em relação à voz, as alterações da respiração, deglutição, mastigação e postura, além de dificuldades na rotina da criança e/ou dinâmica da família, são citadas na literatura como pertencentes aos quadros de disfonia infantil (VIOLA, 2001, PAES, 2005).

Os dados epidemiológicos apontam índice de disfonia na infância da ordem de 6 a $9 \%$, onde os fatores etiológicos são variados e incluem fatores ambientais, físicos e psicológicos, hábitos de vida inadequados, inadaptação fônica, fatores alérgicos, dentre outros. Deste modo, tornam-se importante à avaliação das funções estomatognáticas, estrutura fonoarticulatória, postura corporal e habilidades gerais de comunicação para o diagnóstico vocal (FREITAS; WECKX; PONTES, 2000, MELO et al., 2001, SIMÕES, 2002). FREITAS; WECKX; PONTES, 2000 relataram que os problemas de voz na infância podem ter reflexos no desenvolvimento da capacidade de comunicação adequada socialmente na vida adulta.

Uma vez que o desempenho adequado das funções orais é importante para desenvolvimento craniofacial e psicossocial, promover ações que 
viabilizem o trabalho de adequação das funções orais e da voz, bem como o desenvolvimento de programas de prevenção dos distúrbios miofuncionais orais, tornam-se essenciais para o desenvolvimento da criança.

A Universidade de São Paulo desenvolve um projeto de extensão na cidade de Monte Negro, no estado de Rondônia, e a Faculdade de Odontologia de Bauru participa desse projeto, que tem como um de seus objetivos propor ações preventivas para promoção para a saúde e diagnóstico precoce para o atendimento da população, atingindo todos os níveis de prevenção propostos por LEAVELL; CLARK,1976.

Os Departamentos de Fonoaudiologia, Ortodontia, Odontopediatria e Saúde Coletiva dessa Unidade realizam expedições para esse local periodicamente, identificando, entre outras, as alterações miofuncionais orais nessa comunidade e observando a necessidade de ações na área de Motricidade Orofacial.

Assim, o trabalho visou caracterizar os aspectos miofuncionais orofaciais e vocais crianças do município de Monte Negro/RO. 
2 Materiale Método 



\section{Material e Método}

Esta pesquisa foi aprovada pelo Comitê de Ética em Pesquisa da

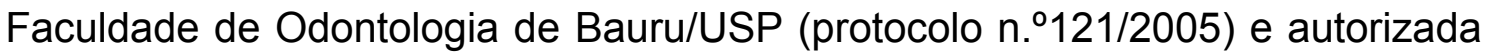
a sua realização pela diretoria da Escola Estadual de Ensino Fundamental Mato Grosso, do município de Monte Negro/RO (Anexos 1 e 2). Após leitura da Carta de Esclarecimento ao Paciente e concordância expressa dos responsáveis com assinatura do Termo de Consentimento Livre e Esclarecido (Anexo 3 e 4), foram iniciadas as avaliações.

\subsection{Casuística}

Utilizando-se da lista de matrícula dos alunos da escola, foram selecionadas, aleatoriamente, 83 crianças residentes na zona urbana do município de Monte Negro/RO, sendo 44 do gênero feminino e 39 do gênero masculino, com idade entre 6 e 11 anos, as quais foram convocadas para submeterem-se à avaliação miofuncional orofacial. Para fins de análise, tendo em vista o período de transição dos dentes (dentadura mista), as crianças foram separadas em 2 grupos: o grupo I (GI), formado por 47 crianças de 6 a 8 anos de idade e o grupo II (GII), constituído por 36 crianças entre 9 e 11 anos de idade (LINDEN, 1990, SOUZA-FREITAS, 1991).

\subsection{Procedimentos}

Todas as crianças foram avaliadas na própria escola, com horário previamente agendado pela pesquisadora. A avaliação constituiu-se da verificação dos aspectos estruturas como: tipo facial e condição dentária, além de aspectos como: postura habitual dos lábios e da língua; estado de contração muscular dos lábios, língua, bochechas, masseteres e mentual; mobilidade e motricidade dos lábios, língua, mandíbula e véu palatino; e das funções de respiração, mastigação, deglutição, fala e voz.

Para auxiliar a análise dos dados, foram filmadas as avaliações da mastigação, deglutição, fala e voz (filmadora JVC, modelo MZN510). Além disso, também foram gravadas as produções vocais (gravador digital da marca Sony, modelo MZN 510). 


\subsubsection{Tipo Facial}

Para a verificação deste aspecto, mediu-se a altura e a largura da face com auxílio da régua milimetrada, sendo que a criança permaneceu sentada em posição frontal durante a avaliação. Para a mensuração da altura, que corresponde à distância entre a glabela e o tecido mole do mento, posicionouse uma régua lateralmente na face e paralelamente à linha média; para a medida da largura, que refere-se à distância entre os dois pontos mais externos das proeminências malares, manteve-se uma régua na posição para a medida da altura e uma outra régua foi posicionada, perpedicularmente à primeira, na região do mento mole, calculando-se a distância do mento mole até a régua lateral e, o valor obtido, foi multiplicado por dois (CAPELOZZA FILHO,1995, VIAZIS, 1996).

A partir das medidas da altura e largura, considerou-se o padrão mesofacial, quando havia equilíbrio entre as medidas (largura igual ou com até $1 \mathrm{~cm}$ de diferença comparado à altura da face); dolicofacial, quando a altura foi maior que a largura e braquifacial, quando a largura prevaleceu sobre a altura (ENLOW, 1998, BIANCHINI, 1998).

\subsubsection{Relação Dentária}

Nesta avaliação, os dentes foram contados mediante inspeção visual, a fim de ser verificado se haviam falhas dentárias ou se todos os elementos dentários previstos estavam presentes, assim como o estado de conservação dos mesmos. Também se observou a relação ântero-posterior dos molares decíduos ou permanentes (ANGLE, 1899) e a relação dos arcos dentários nos planos transversal, horizontal e vertical, para verificar a presença ou não de mordida aberta, trespasse vertical e horizontal aumentados ou mordida cruzada (TOMITA; BIJELLA; FRANCO, 2000). Utilizando-se de lápis cópia e régua milimetrada, mensurou-se os trespasses vertical e horizontal, considerando-se as medidas entre $1 \mathrm{~mm}$ e $4 \mathrm{~mm}$ dentro da normalidade (LANGLADE, 1995, HENRIKSON; EKBERG; NILNER, 1997, FERREIRA, 2004). 


\subsubsection{Postura Habitual dos Lábios e da Língua}

A posição habitual de repouso dos lábios e da língua foi verificada por meio de observação, durante todo o processo de avaliação. Também foi solicitado, às crianças, que relatassem sobre a posição e o local de possível permanência da língua (JUNQUEIRA, 1997, CAMPIOTTO, 1998).

Considerou-se nesta avaliação se os lábios encontravam-se selados com ou sem tensão, entreabertos ou abertos e se a língua apresentava-se com o ápice na papila palatina, na região alveolar inferior ou entre os dentes. A posição dos lábios selados sem tensão e a língua na papila palatina foram consideradas adequadas (JUNQUEIRA, 1997).

\subsubsection{Estado de Contração Muscular}

Verificou-se neste aspecto, por meio observação e palpação digital, a contração muscular dos lábios, língua, bochechas, masseter e mentual. O grau de tensão muscular foi classificado como adequado ou alterado, sendo este último classificado como pouco diminuído, diminuído, pouco aumentado ou aumentado (CAMPIOTTO, 1998, BIANCHINI, 2001).

\subsubsection{Mobilidade e Motricidade}

Este aspecto foi avaliado a partir da observação funcional e testes de movimentos dirigidos para lábios, língua, mandíbula e véu palatino, a partir de ordens motoras ou, quando necessário, sob modelo do avaliador.

Quanto aos lábios, foram analisados os movimentos de estalo, vibração, lateralização protruido, protrusão, retração, elevação do lábio superior e abaixamento do inferior, além da emissão da seqüência de sílabas /pa/ / $\mathrm{u} / / \mathrm{si} /$ /su/ /Ji/ /pa/.

Para a verificação dos movimentos da língua, solicitou-se à criança a realização das atividades: estalo, protrusão/retração, vibração, rotação interna e externa, pontos cardeais e elevação do dorso da língua. 
Quanto ao véu palatino, foi solicitada a emissão prolongada e entrecortada da vogal /a/, observando-se a movimentação e a simetria do movimento (GENARO; YAMASHITA; TRINDADE, 2004, JUNQUEIRA, 2004).

Cada movimento testado foi classificado como adequado, se realizado sem dificuldades, ou seja, de forma coordenada, precisa e seguindo o ritmo solicitado, ou alterado, quando não atendia aos requisitos citados, para dois ou mais movimentos testados.

No que se refere à avaliação da mandíbula, solicitou-se a abertura e fechamento desta e, foi considerado alterado quando observado desvio na trajetória e presença de ruídos na articulação temporomandibular, bem como imprecisão dos movimentos (BERRETIN-FELIX; JORGE; GENARO, 2004, BIANCHINI, 2001).

\subsubsection{Respiração}

$\mathrm{Na}$ avaliação deste aspecto foi considerado o modo e o tipo respiratório e a criança encontrava-se sentada durante esse procedimento. Quanto ao modo, foi verificado se o mesmo era realizado por via nasal, oro nasal ou oral, a partir da observação de algum ponto de selamento na cavidade oral, verificando-se a posição dos lábios, da mandíbula e da língua. Além disso, posicionou-se o espelho de Glatzel logo abaixo das narinas da criança durante a respiração de repouso, para a visualização do fluxo aéreo expiratório nasal, bem como da simetria do mesmo, observando-se o embaçamento do espelho, representado pela condensação das partículas de ar sobre o mesmo (JUNQUEIRA, 2004, BERRETIN-FELIX; JORGE; GENARO, 2004).

No que se refere ao tipo respiratório, foi verificado se o mesmo era completo, médio, superior ou inferior, a partir da observação, assim como do apoio das mãos do avaliador nas regiões torácica e abdominal da criança, para a percepção e constatação da movimentação dessas regiões (BEHLAU et al., 2001, LE HUCHE; ALLALI, 2005).

Considerou-se adequado o modo respiratório nasal e os tipos respiratórios completo, médio, ou inferior (BEHLAU et al., 2001, LE HUCHE; ALLALI, 2005), e alterados os modos respiratórios oro nasal e oral e o tipo respiratório superior (JUNQUEIRA, 2004, ZEMLIN, 2005). 


\subsubsection{Mastigação}

A função mastigatória foi verificada por meio da observação no momento da avaliação, bem como em um segundo momento, durante a análise da filmagem desse procedimento.

Foi oferecido à criança uma porção inteira de biscoito do tipo waffer para que a mesma realizasse mastigação habitual. Observou-se a apreensão do alimento e o local da incisão do mesmo, se anterior, lateral ou posterior; a postura dos lábios, se selados, abertos assistematicamente ou sistematicamente; o tipo mastigatório, classificado como bilateral alternado ou simultâneo, unilateral preferencial ou crônico; a formação do bolo alimentar, se completa, incompleta ou ausente (SCHNEIDER; SENGER, 2001, WHITAKER, 2005). Para a verificação da formação do bolo alimentar, na última porção desse alimento era solicitado que a criança, antes de deglutir, abrisse a boca para ser verificado esse aspecto.

Classificou-se a mastigação como adequada, quando havia apreensão anterior do alimento, lábios selados e formação completa do bolo alimentar (TOMÉ et al., 2000, FELÍCIO, 2004, JUNQUEIRA, 2004, WHITAKER, 2005), bem como tipo mastigatório bilateral alternado ou unilateral preferencial à direita ou esquerda ( $66 \%$ a $95 \%$ do número de ciclos), conforme proposto por TAY,1994.

Também foi oferecido uma porção de biscoito do tipo waffer com tamanho padronizado $(2,5 \mathrm{~cm}$ de comprimento), a fim de ser cronometrado o tempo mastigatório, do momento da colocação do alimento sobre a língua até a primeira deglutição, determinada pela elevação da laringe (DUARTE, 2003, WHITAKER, 2005, MELO et al., 2006).

Para a classificação de padrão adequado ou alterado, foram tomados como referência os estudos de MOTTA, 2002 e MELO et al. 2006, sendo calculado a média do tempo mastigatório de todas as crianças $(13,09 \mathrm{~s})$, acrescentando-se ou diminuindo-se $25 \%$ deste valor. Deste modo, o tempo mastigatório foi classificado como lento quando o valor era superior a 16.36s e, como rápido, quando este valor era inferior a 9.82s. 


\subsubsection{Deglutição}

Este aspecto foi verificado utilizando-se de sólido (biscoito do tipo waffer) e de líquido (água), a partir da observação no momento da avaliação e também durante a análise da filmagem.

A avaliação desta função foi realizada em duas situações, sendo a primeira durante a avaliação da mastigação (sólido), e também oferecendo-se uma porção de alimento sólido e solicitado que a criança deglutisse somente após a instrução do avaliador (CAMPIOTTO, 1998, BIANCHINI, 2001). Quando necessário, o avaliador abaixava levemente o lábio inferior no momento da deglutição, a fim de observar a presença ou não de pressionamento ou interposição da língua. Além disso, após a deglutição, solicitava-se à criança que abrisse a boca para se verificar a presença de resíduos (SCHNEIDER; SENGER, 2001).

O teste para a deglutição de líquido também foi analisado em duas situações, primeiramente era solicitado que a criança ingerisse um pouco de água de forma habitual e, em outra situação, semelhante à deglutição do sólido, era solicitado que a criança deglutisse o líquido somente a partir do comando do avaliador (BIANCHINI, 2001, JUNQUEIRA, 2004). Nesse momento, se necessário, o mesmo abaixava levemente o lábio inferior, para observar a presença ou não de pressionamento ou interposição da língua (BROWN, 1996).

Foram identificadas, durante a avaliação das duas consistências (líquido e sólido), atipias ou adaptações, como padrões indesejáveis, sendo observado pressionamento ou interposição da língua, interposição labial, participação da musculatura orbicular e de mentual, bem como presença de resíduos após a deglutição, caracterizando-se estas como padrão alterado (MARCHESAN, 1999, BIANCHINI, 2001, MOTTA, 2002, JUNQUEIRA, 2004). A ausência de tais comportamentos foi considerada adequada.

\subsubsection{Fala}

Foram filmadas para posterior analise, amostra de fala espontânea, contagem de números até 20 , repetição de frases e nomeação de figuras temáticas (YAVAS et al., 1991, MOTA, 2001). 
Analisou-se esta função em relação à produção articulatória fonética, considerando-se a presença de ceceio, projeção anterior ou lateral da língua, troca de ponto articulatório e mímica facial excessiva, bem como desvios mandibulares (BIANCHINI, 2001). Além disso, verificou-se a presença de simplificações fonológicas, como omissão, anteriorização, posteriorização, oclusivação, dessonorização, reduplicação, assimilação, migração, semivocalização e redução (WERTZNER, 2001, CASTRO; WERTZNER, 2006). As trocas culturais não foram consideradas como alterações (CASTRO; WERTZNER, 2006).

Analisou-se, também, a precisão articulatória, classificando o tipo articulatório como fechado, exagerado, impreciso e preciso, sendo o último considerado adequado (CAMPIOTTO, 1998, BIANCHINI, 2001).

\subsubsection{Voz}

Este aspecto foi avaliado por meio de uma amostra de fala espontânea e contagem de números, as quais foram filmadas, assim como a partir da emissão das vogais sustentadas /a/, /i/, /u/ e das consoantes /s/ e /z/, as quais foram gravadas em MD, com o microfone posicionado lateralmente à $10 \mathrm{~cm}$ da comissura labial.

Para a verificação do tempo máximo fonatório (TMF) solicitou-se três emissões sustentadas das vogais /a/, /i/, /u/, sendo calculado a média dos três valores, bem como solicitado uma emissão das consoantes /s/ e /z/, afim de ser calculada a relação s/z (FINNEGAN, 1985 ROCKENBACH; FEIJÓ, 2000). Esses procedimentos eram realizados após inspiração e solicitando-se que a mesma fosse realizada o mais longa possível. Os valores de referência para a emissão das vogais seguem a idade da criança, em anos (BEHLAU, 2001). Para o cálculo da relação $s / z$, considerou-se os valores entre 0,8 e 1,2 segundos como adequados e, abaixo de 0,8 segundos ou acima de 1,2 segundos como alterados (GAMBOA et al., 1995, BEHLAU, 2001).

Além disso, também foi realizada análise perceptivo-auditiva referente à coordenação pneumofonoarticulatória (CPFA), ao sistema de ressonância e à qualidade vocal. Para análise da qualidade vocal foi utilizado o G - grau global 
da disfonia da Escala GRBAS, considerando-se adequado o grau global igual a zero, caracterizado pela ausência de disfonia (HIRANO, 1981).

A CPFA foi considerada inadequada quando observado o uso excessivo de ar durante a fonação e hiperconstrição da musculatura laríngea (BEHLAU, 2001), observado pela ocorrência do uso de ar de reserva e decréscimo do volume à medida que se fala (OLIVEIRA, 2004); analisados a partir da amostra da fala espontânea e da contagem de números.

Quanto ao sistema de ressonância, também analisado a partir da amostra da fala espontânea e da contagem de números, considerou-se adequado quando havia equilíbrio entre as cavidades de ressonância e alterado quando houvesse concentração maior de ressonância em uma determinada cavidade; caracterizando-se, assim, como excessivo laríngeo, nasal ou faríngeo, ou insuficiente nasal (BEHLAU, 2001).

Para a análise perceptivo-auditiva, quanto à CPFA, ao sistema de ressonância e à qualidade vocal, três juizes especialistas na área de voz, ouviram as amostras de fala e classificaram cada aspecto. Foi, então, aplicado a estatística Kappa, a fim de se verificar a concordância inter juizes em cada aspecto avaliado. $\mathrm{Na}$ análise da CPFA, a estatística Kappa variou de 0,29 a 0,49 (razoável a moderada); para o sistema de ressonância variou de 0,58 a 0,84 (de moderada a muito boa) e, para a qualidade vocal (G) esteve entre 0,28 e 0,59 (razoável a moderada). Para todos os aspectos considerou-se o valor de $p<0,05$ como significante. 
3 Resultados 



\section{Resultados}

Neste capítulo encontram-se descritos os resultados das avaliações realizadas quanto aos aspectos: tipo facial, relação dentária, postura habitual dos lábios e da língua, estado de contração muscular, mobilidade e motricidade, assim como das funções de respiração, mastigação, deglutição, fala e voz, para os dois grupos de crianças avaliadas: GI (6 a 8 anos) e GII (9 a 11 anos).

\subsection{Tipo Facial}

Quanto ao tipo facial, no grupo I há maior ocorrência de mesofacial (74\%) que dolicofacial (26\%) e, no grupo II, há distribuição mais equilibrada entre os tipos mesofacial (58\%) e dolicofacial (42\%), não sendo observado, nos dois grupos estudados, tipo braquifacial (Gráfico 1).

Gráfico 1. Distribuição da amostra de acordo com o tipo facial para os dois grupos estudados

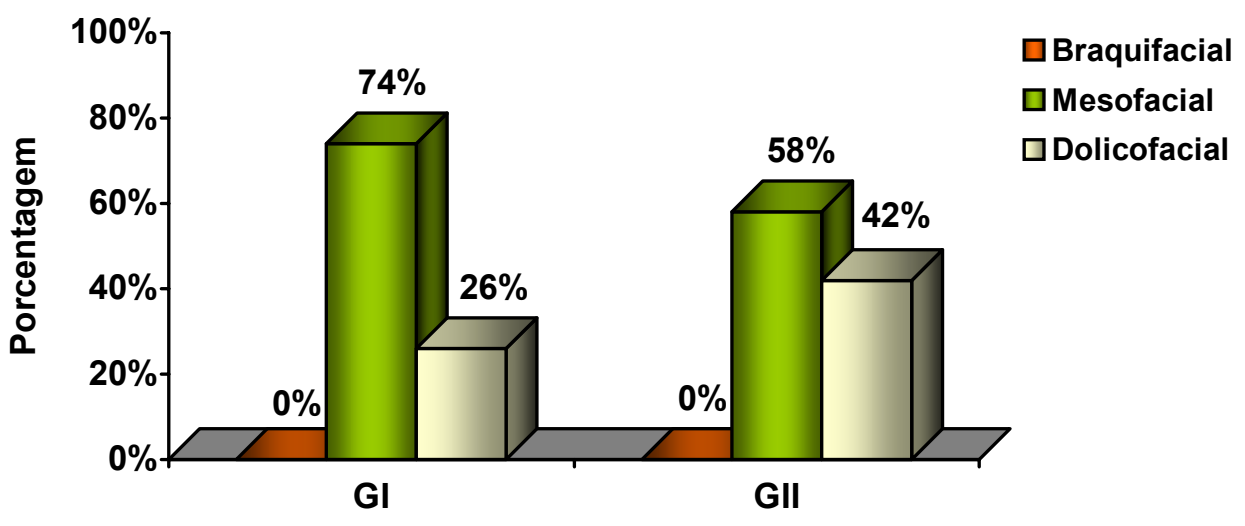

\subsection{Relação Dentária}

No gráfico 2 estão apresentados os resultados relativos a esse aspecto, verificando-se que o grupo I demonstrou maior ocorrência de alteração (60\%) que o grupo II (42\%). Quanto aos tipos de alteração, estas não excederam 20\% em ambos os grupos (tabela 1), verificando-se que a maior ocorrência foi de alteração horizontal, tanto para o grupo I (19\%) quanto para o grupo II (20\%), 
seguida da alteração vertical anterior (15\% para GI e $8 \%$ para GII), tipos combinados (15\% para GI e 8\% para GII), alteração transversal (9\% para GI e $6 \%$ para GII) e alteração vertical posterior ( $2 \%$ para GI).

Gráfico 2. Distribuição da amostra segundo a relação adequada ou alterada dos arcos dentários para os grupos estudados

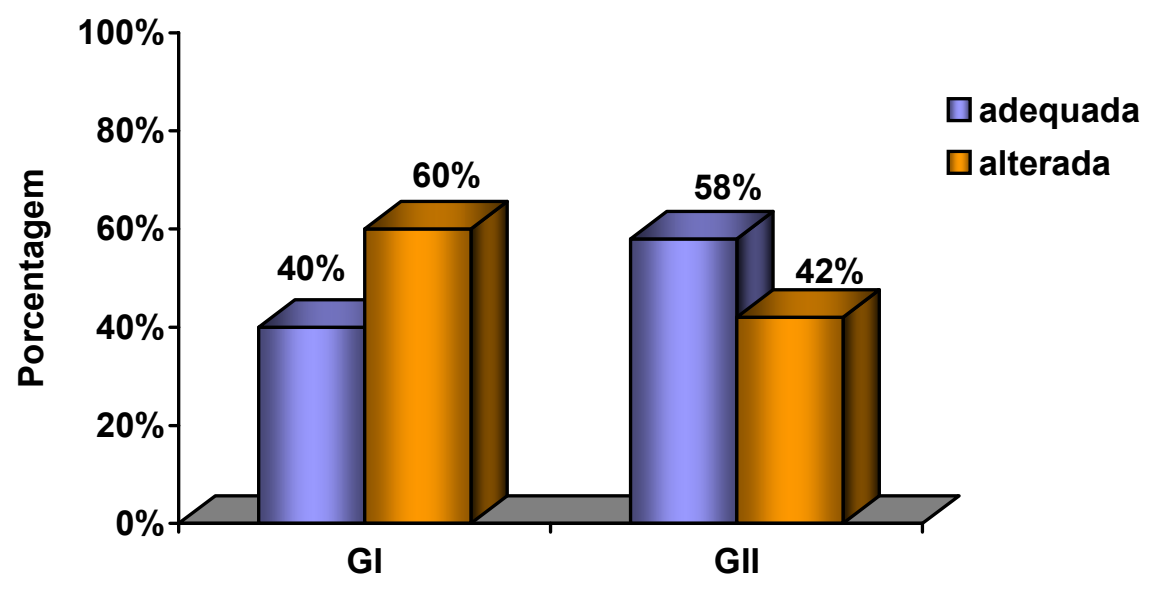

Tabela 1. Tipos de alteração na relação dentária para os grupos I e II

\begin{tabular}{lll}
\hline \multicolumn{1}{c}{ Tipos de Alteração } & \multicolumn{1}{c}{ GI } & GII \\
\hline Vertical anterior & $15 \%(n=7)$ & $8 \%(n=3)$ \\
Vertical posterior & $2 \%(n=1)$ & $0 \%(n=0)$ \\
Horizontal & $19 \%(n=9)$ & $20 \%(n=7)$ \\
Transversal & $9 \%(n=4)$ & $6 \%(n=2)$ \\
Tipos Combinados & $15 \%(n=7)$ & $8 \%(n=3)$ \\
Total & $\mathbf{6 0 \% ( n = 2 8 )}$ & $\mathbf{4 2 \% ( n = 1 5 )}$ \\
\hline \hline
\end{tabular}




\subsection{Postura Habitual dos Lábios e da Língua}

Em relação à postura habitual dos lábios e da língua, observou se estas apresentavam a postura habitual adequada ou alterada. Embora haja equivalência de alterações entre os grupos, nota-se maior ocorrência na postura habitual da língua, comparado à postura dos lábios.

O gráfico 3 apresenta os resultados quanto à postura habitual dos lábios, observando-se que, em ambos os grupos, prevaleceu a postura alterada, em mais da metade das crianças avaliadas. O tipo de alteração mais observado em ambos os grupos foi lábios entreabertos (60\% para GI e $53 \%$ para GII), conforme verificado na tabela 2 .

Gráfico 3. Distribuição da amostra segundo a postura habitual adequada ou alterada dos lábios para os dois grupos estudados

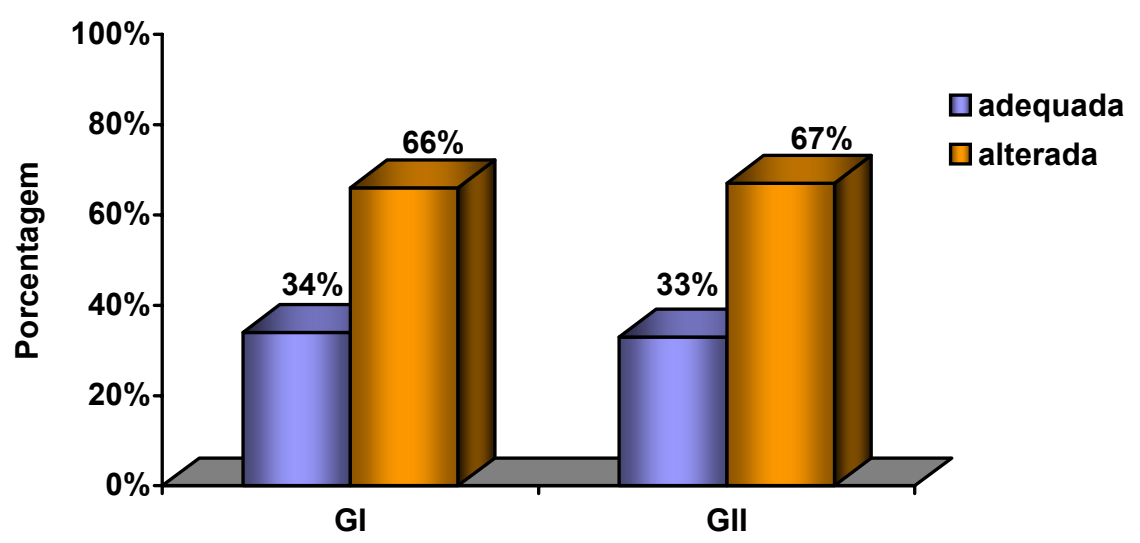

Tabela 2. Tipos de alteração na postura dos lábios para os grupos I e II

\begin{tabular}{lll}
\hline Tipos de Alteração & \multicolumn{1}{c}{ GI } & GII \\
\hline Selados com tensão & $2 \%(n=1)$ & $8 \%(n=3)$ \\
Entreabertos & $60 \%(n=28)$ & $53 \%(n=19)$ \\
Abertos & $4 \%(n=2)$ & $6 \%(n=2)$ \\
Total & $\mathbf{6 6 \% ( n = 3 1 )}$ & $\mathbf{6 7 \% ( n = 2 4 )}$ \\
\hline
\end{tabular}

Quanto à postura habitual da língua, os resultados observados no gráfico 4 evidenciam predomínio de alteração para a maioria das crianças de 
ambos os grupos. Das alterações encontradas, a postura na região alveolar inferior foi observada em pouco mais da metade da amostra nos dois grupos, e entre os dentes em aproximadamente $1 / 4$ da amostra em ambos os grupos (tabela 3).

Gráfico 4. Distribuição da amostra segundo a postura habitual adequada ou ou alterada da língua para os dois grupos estudados

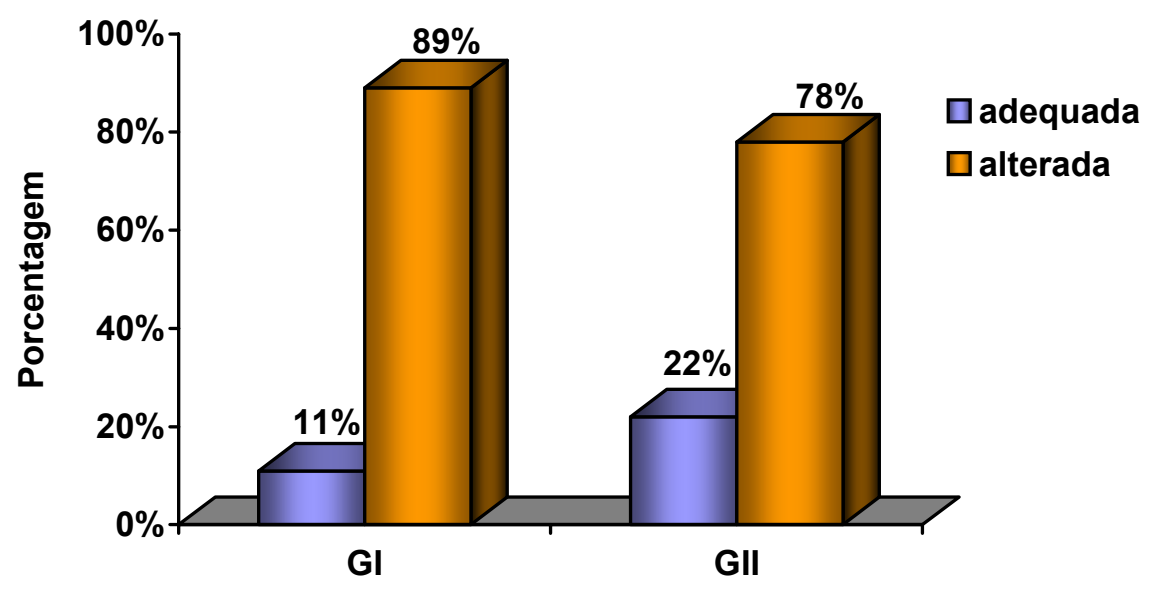

Tabela 3. Tipos de alteração na postura da língua para os grupos I e II

\begin{tabular}{lcl}
\hline Tipos de Alteração & GI & GII \\
\hline Região alveolar inferior & $64 \%(n=30)$ & $58 \%(n=21)$ \\
Entre os dentes & $25 \%(n=12)$ & $20 \%(n=7)$ \\
Total & $\mathbf{8 9 \% ( n = 4 2 )}$ & $\mathbf{7 8 \% ( n = 2 8 )}$ \\
\hline
\end{tabular}




\subsection{Estado de Contração Muscular}

Os resultados deste aspecto podem ser visualizados no gráfico 5 , referente ao grupo I e no gráfico 6 referente ao grupo II. Há predomínio de alteração do estado de contração muscular na maioria das crianças, no que se refere à bochecha, lábio e língua, relacionada à diminuição do estado de contração muscular (tabelas 4 e 5). Quanto ao mentual, a ocorrência de alteração e normalidade mostrou-se aproximada no grupo II e, no grupo I, houve predomínio de normalidade $(70 \%)$. Das alterações observadas, em ambos os grupos, estas se referem ao aumento do estado de contração muscular (tabelas 4 e 5). Em relação ao masseter, a ocorrência de alteração foi observada em menos da metade da amostra, em ambos os grupos, verificando-se pouco diminuído ( $27 \%$ para $\mathrm{Gl}$ e $14 \%$ para GII) e pouco aumentado ( $8 \%$ para $\mathrm{GI}$ e $30 \%$ para GII), conforme mostra as tabelas 4 e 5 .

Gráfico 5. Distribuição da amostra de acordo com o estado de contração muscular adequado ou alterado para o grupo I

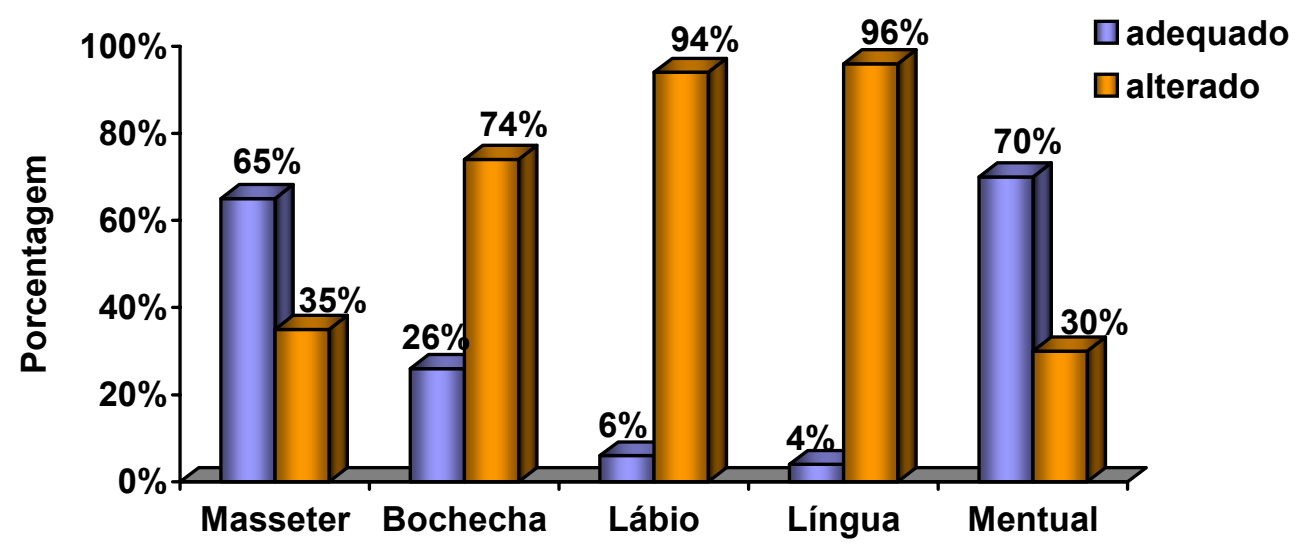


Gráfico 6. Distribuição da amostra de acordo com o estado de contração muscular adequado ou alterado para o grupo II

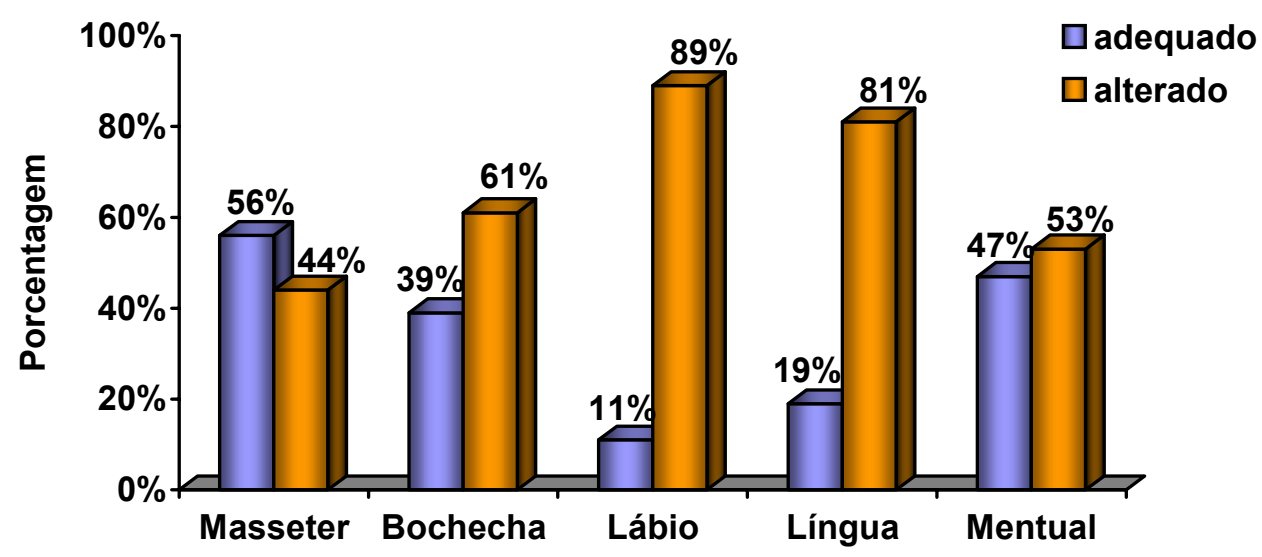

Tabela 4. Alteração quanto ao estado de contração muscular no grupo I

\begin{tabular}{llllll}
\hline Tipos de Alteração & Masseter & Bochecha & Lábio & Língua & Mentual \\
\hline Pouco diminuído & $27 \%(n=13)$ & $51 \%(n=24)$ & $45 \%(n=21)$ & $51 \%(n=24)$ & $0 \%(n=0)$ \\
Diminuído & $0 \%(n=0)$ & $21 \%(n=10)$ & $49 \%(n=23)$ & $45 \%(n=21)$ & $0 \%(n=0)$ \\
Pouco aumentado & $8 \%(n=4)$ & $2 \%(n=1)$ & $0 \%(n=0)$ & $0 \%(n=0)$ & $15 \%(n=7)$ \\
Aumentado & $0 \%(n=0)$ & $0 \%(n=0)$ & $0 \%(n=0)$ & $0 \%(n=0)$ & $15 \%(n=7)$ \\
\multicolumn{1}{c}{ Total } & $\mathbf{3 5 \% ( n = 1 7 )}$ & $\mathbf{7 4 \% ( n = 3 5 )}$ & $\mathbf{9 4 \% ( n = 4 4 )}$ & $\mathbf{9 6 \% ( n = 4 5 )}$ & $\mathbf{3 0 \% ( n = 1 4 )}$
\end{tabular}

Tabela 5. Alteração quanto ao estado de contração muscular no grupo II

\begin{tabular}{llllll}
\hline Tipos de Alteração & Masseter & Bochecha & Lábio & Língua & Mentual \\
\hline Pouco diminuído & $14 \%(n=5)$ & $44 \%(n=16)$ & $44 \%(n=16)$ & $53 \%(n=19)$ & $0 \%(n=0)$ \\
Diminuído & $0 \%(n=0)$ & $17 \%(n=6)$ & $42 \%(n=15)$ & $28 \%(n=10)$ & $0 \%(n=0)$ \\
Pouco aumentado & $30 \%(n=11)$ & $0 \%(n=0)$ & $3 \%(n=1)$ & $0 \%(n=0)$ & $36 \%(n=13)$ \\
Aumentado & $0 \%(n=0)$ & $0 \%(n=0)$ & $0 \%(n=0)$ & $0 \%(n=0)$ & $17 \%(n=6)$ \\
\multicolumn{1}{c}{ Total } & $\mathbf{4 4 \% ( n = 1 7 )}$ & $\mathbf{6 1 \% ( n = 2 2 )}$ & $\mathbf{8 9 \% ( n = 3 2 )}$ & $\mathbf{8 1 \% ( n = 2 9 )}$ & $\mathbf{5 3 \% ( n = 1 9 )}$
\end{tabular}




\subsection{Mobilidade e Motricidade}

No que se refere à mobilidade e motricidade, os resultados estão descritos nos gráficos 7 e 8, respectivamente para os grupos I e II. Em relação aos lábios e língua, no grupo I nota-se ocorrência semelhante entre adequação e alteração. Quando havia alteração nesse aspecto, em relação ao lábio, observou-se maior ocorrência de dificuldade, ao redor de $40 \%$, para os movimentos de abaixamento do lábio inferior, elevação do lábio superior, lateralização dos lábios protruídos, bem como para a emissão da seqüência das sílabas /pa/ / Ju/ /si//su/ /ji//pa/ e, quanto a dificuldade de movimentação da língua, as maiores ocorrências, verificada em aproximadamente metade dos casos, referem-se à vibração e elevação do dorso da língua (tabelas 5 e 6). Já em relação ao grupo II, nota-se pequena ocorrência de alteração para lábios $(22 \%)$ e língua (33\%). Em relação às dificuldades observadas, estas se assemelham às apresentadas pelo grupo I, porém com menor ocorrência (tabelas 5 e 6 ).

Quanto ao movimento mandibular, observou-se no grupo I pouca ocorrência de alteração (13\%) em relação ao grupo II (33\%). Das alterações observadas, estas se referem à desvio na trajetória, sendo pouco maior a ocorrência para o grupo II (28\%) que para o grupo I (11\%), e presença de ruídos articulares, com ocorrência similar entre os grupos I (2\%) e II $(5 \%)$, conforme visualizado na tabela 7 .

Em relação à movimentação do véu palatino, observou-se normalidade para todas as crianças de ambos os grupos.

Gráfico 7. Distribuição da amostra segundo a mobilidade e motricidade adequada ou alterada para o grupo I

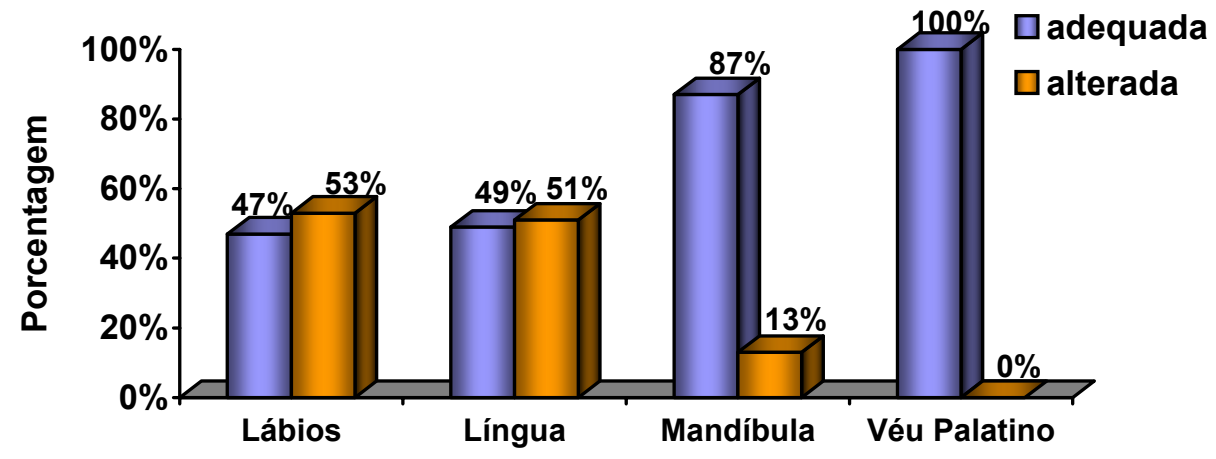


Gráfico 8. Distribuição da amostra segundo a mobilidade e motricidade adequada ou alterada para o grupo II.

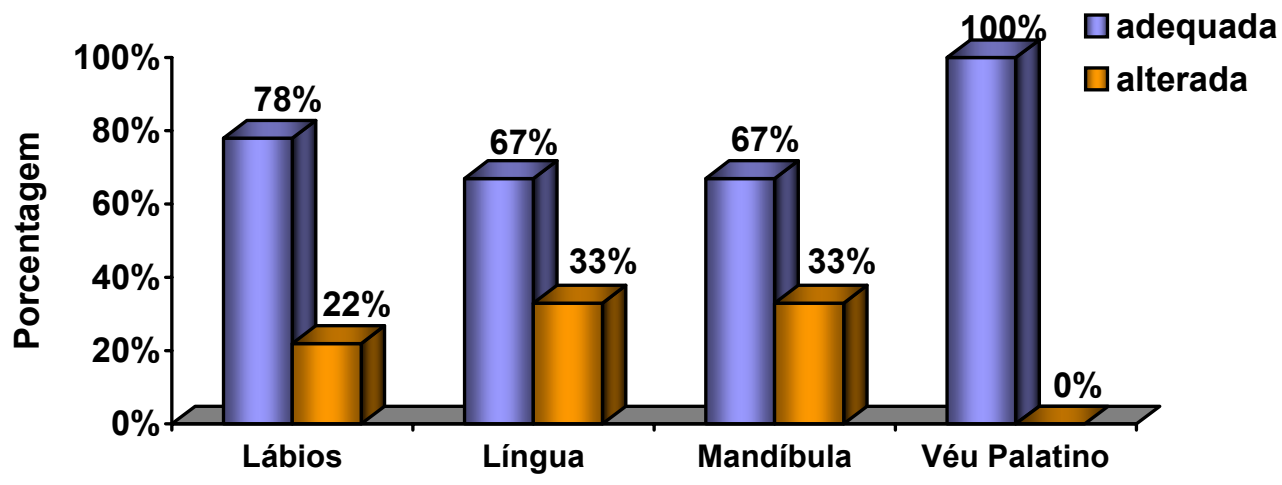

Tabela 5. Alteração na mobilidade e motricidade de lábios nos grupos I e II

\begin{tabular}{lll}
\hline \multicolumn{1}{c}{ Grupos } & \multicolumn{1}{c}{ G I } & \multicolumn{1}{c}{ GII } \\
\hline Estalo & $9 \%(n=4)$ & $11 \%(n=4)$ \\
Vibração & $11 \%(n=5)$ & $6 \%(n=2)$ \\
Lateralização Protruído & $34 \%(n=16)$ & $22 \%(n=8)$ \\
Protrusão & $11 \%(n=5)$ & $0 \%(n=0)$ \\
Retração & $2 \%(n=1)$ & $3 \%(n=1)$ \\
Elevação do Superior & $38 \%(n=18)$ & $14 \%(n=5)$ \\
Abaixamento do Inferior & $40 \%(n=19)$ & $25 \%(n=9)$ \\
/pa/ /Ju/ /si//su/ / $\mathrm{i} / /$ pa/ & $40 \%(n=19)$ & $11 \%(n=4)$ \\
\hline
\end{tabular}

Tabela 6. Alteração na mobilidade e motricidade da língua nos grupos I e II

\begin{tabular}{lll}
\hline \multicolumn{1}{c}{ Grupos } & \multicolumn{1}{c}{ G I } & \multicolumn{1}{c}{ GII } \\
\hline Estalo & $21 \%(n=10)$ & $6 \%(n=2)$ \\
Protrusão/Retração & $8 \%(n=4)$ & $6 \%(n=2)$ \\
Vibração & $49 \%(n=23)$ & $27 \%(n=10)$ \\
Rotação Interna & $19 \%(n=9)$ & $11 \%(n=4)$ \\
Rotação Externa & $15 \%(n=7)$ & $11 \%(n=4)$ \\
Pontos Cardeais & $23 \%(n=11)$ & $6 \%(n=2)$ \\
Elevação do Dorso & $45 \%(n=21)$ & $19 \%(n=7)$ \\
\hline
\end{tabular}


Tabela 7. Alteração na mobilidade e motricidade mandibular nos grupos I e II

\begin{tabular}{lll}
\hline \multicolumn{1}{c}{ Grupos } & \multicolumn{1}{c}{ G I } & \multicolumn{1}{c}{ GII } \\
\hline Desvio na trajetória & $11 \%(n=5)$ & $28 \%(n=10)$ \\
Ruídos na ATM & $2 \%(n=1)$ & $5 \%(n=2)$ \\
\hline
\end{tabular}

\subsection{Respiração}

$\mathrm{Na}$ avaliação da função respiratória, considerou-se adequado ou alterado quanto ao modo e tipo respiratório para os grupos I (gráfico 9) e II (gráfico 10). A respeito do modo respiratório, observou-se alteração em pouco menos da metade da amostra no grupo II (45\%), observando respiração oro nasal $(42 \%)$ e respiração oral (3\%). Já para o grupo I, há maior ocorrência de alteração $(62 \%)$, tendo sido observado respiração oro nasal (53\%) e respiração oral $(9 \%)$.

Em relação do tipo respiratório, nota-se ocorrência de alteração em menos da metade da amostra, sendo maior para o grupo I. Das alterações encontradas, estas se referem ao tipo superior.

Gráfico 9. Distribuição da amostra quanto ao modo e tipo adequado ou alterado da função respiratória para o grupo I

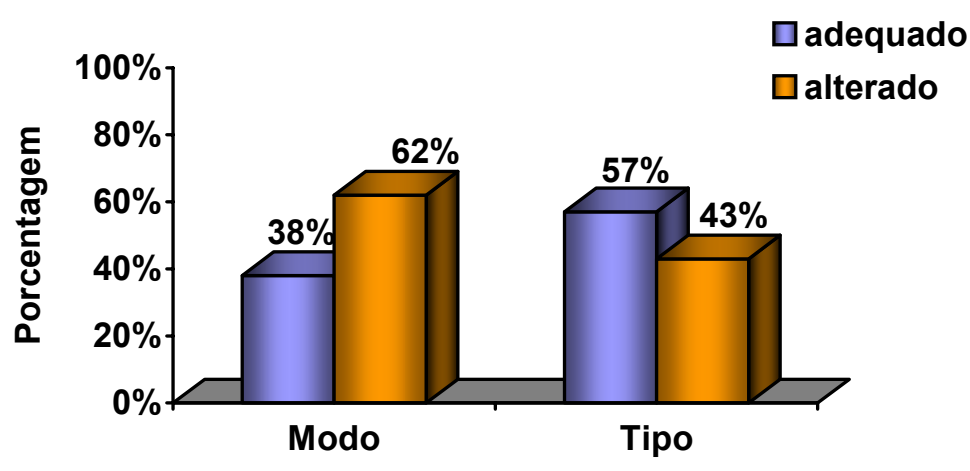


Gráfico 10. Distribuição da amostra quanto ao modo e tipo adequado ou alterado da função respiratória para o grupo GII

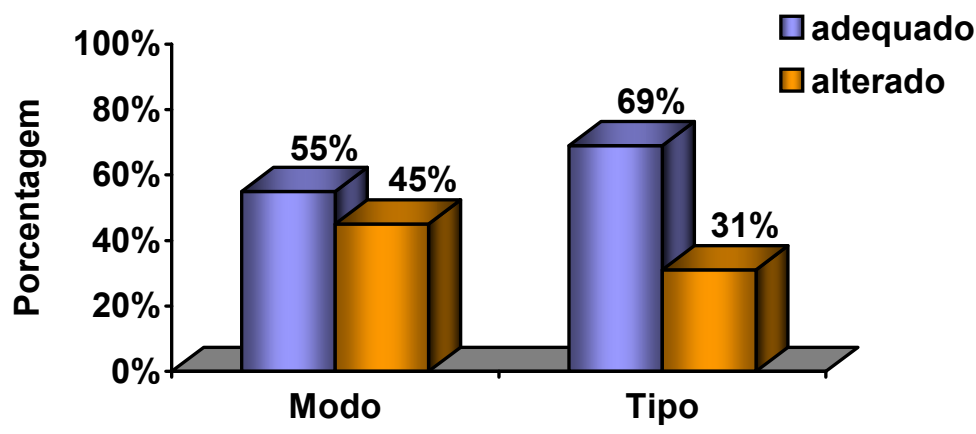

\subsection{Mastigação}

$\mathrm{Na}$ avaliação da função mastigatória, considerou-se o padrão adequado ou alterado para os grupos I (gráfico 11) e II (gráfico 12). Observou-se que, para a grande maioria dos aspectos avaliados (apreensão, postura labial, tipo e tempo mastigatório), predominou a adequação, em ambos os grupos.

Quando as alterações estavam presentes, no grupo I, a postura labial, o tipo e o tempo mastigatório apresentaram ocorrência próximo a $30 \%$. Em relação à postura labial alterada (28\%), esta se relacionava a lábios afastados, às vezes; quanto ao tipo mastigatório alterado (28\%), verificou-se mastigação unilateral crônica (21\%) e mastigação anterior (7\%); já, a alteração do tempo mastigatório $(34 \%)$ relacionou-se à mastigação mais lenta $(21 \%)$ e mais rápida (13\%). A alteração na apreensão do alimento foi a de menor ocorrência (17\%), referindo-se à apreensão lateral.

As alterações observadas no grupo II tiveram menor ocorrência em relação ao grupo I para a postura labial (11\%), sendo verificado lábios afastados às vezes, bem como para o tipo mastigatório (11\%), observando-se mastigação unilateral crônica (5\%), mastigação simultânea (3\%) e mastigação anterior (3\%). Não se verificou, nesse grupo, alteração na apreensão do alimento e, quanto ao tempo mastigatório, verificou-se ocorrência de alteração de $28 \%$, sendo observado mastigação mais lenta $(11 \%)$ e mais rápida $(17 \%)$. 
O único aspecto em que prevaleceu a alteração, em ambos os grupos, sendo um pouco mais elevada à ocorrência de alteração para o grupo I (79\%) que para o grupo II (61\%), refere-se à formação do bolo alimentar. Das alterações encontradas, estas se relacionam à formação incompleta do bolo alimentar (55\% para GI e 44\% para GII) e ausência de formação do bolo (24\% para GI e $17 \%$ para GII).

Gráfico 11. Distribuição da amostra de acordo com a função mastigatória adequada ou alterada para o grupo I

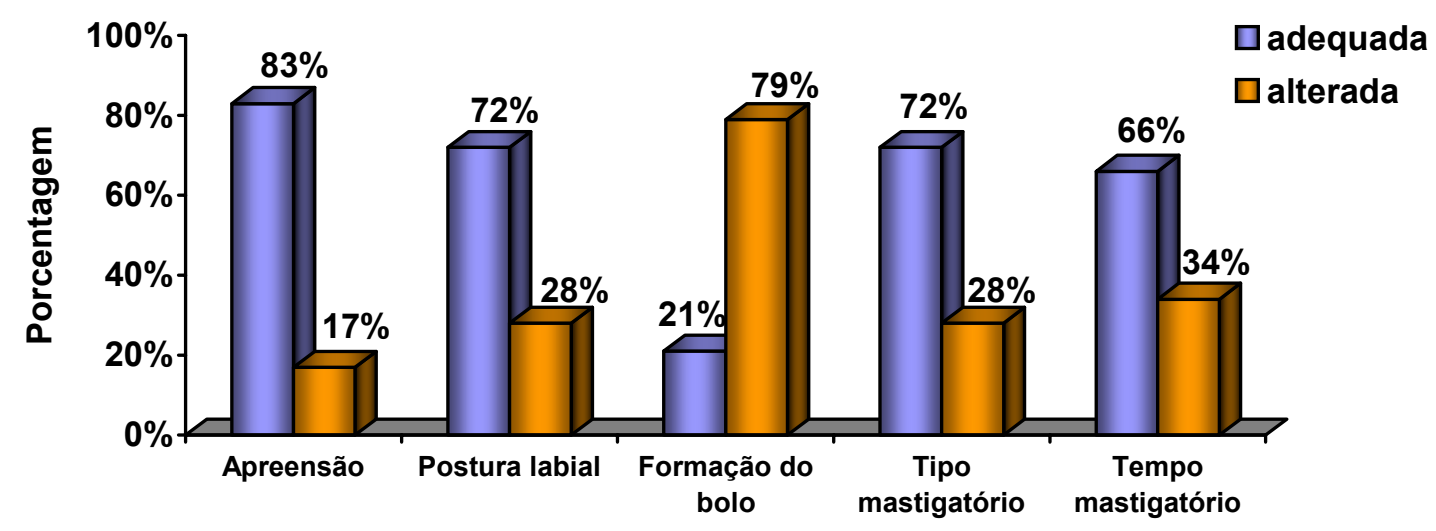

Gráfico 12. Distribuição da amostra de acordo com a função mastigatória adequada ou alterada para o grupo II

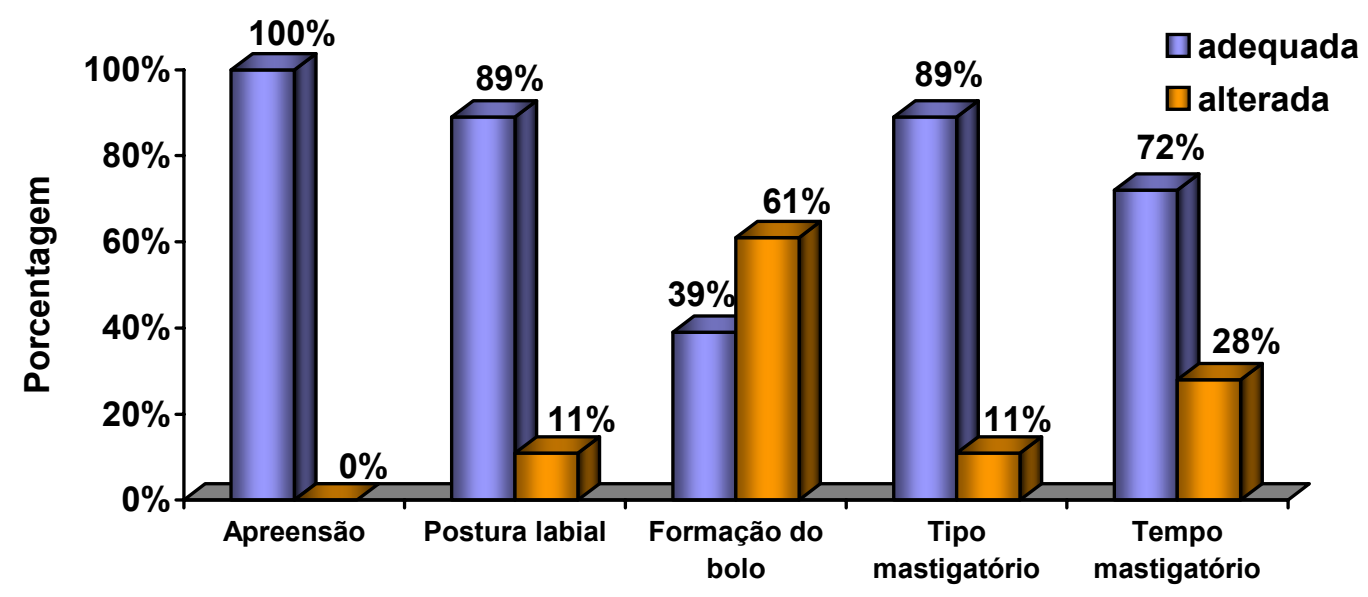




\subsection{Deglutição}

Quanto à função de deglutição, foi analisada a presença ou ausência de alteração, observando-se o pressionamento ou interposição lingual, a participação de orbicular e de mentual, assim como presença de resíduos após a realização desta função, tanto para o grupo I (gráficos 13), quanto para o grupo II (gráfico 14).

À exceção do pressionamento lingual no grupo I e da presença de resíduos após a deglutição no grupo II, as demais alterações da deglutição investigadas (interposição lingual, participação de orbicular e de mentual) estiveram presentes em mais da metade das crianças nos dois grupos avaliados. Observou-se ocorrência próxima entre os grupos para participação de orbicular ( $77 \%$ no GI e $72 \%$ no GII) e de mentual (68\% no GI e $64 \%$ no GII) e, quanto à interposição lingual, no grupo I observou-se maior ocorrência de alteração (85\%) comparado ao grupo II (56\%). Em relação ao pressionamento lingual, a ocorrência desta alteração foi mais acentuada no grupo II (58\%) que no grupo I $(23 \%)$. Verificou-se, também, a presença de resíduos após a deglutição para $57 \%$ das crianças do grupo I e $44 \%$ das crianças do grupo II.

Gráfico 13. Distribuição da amostra segundo a presença ou ausência de alteração da função de deglutição para o grupo I

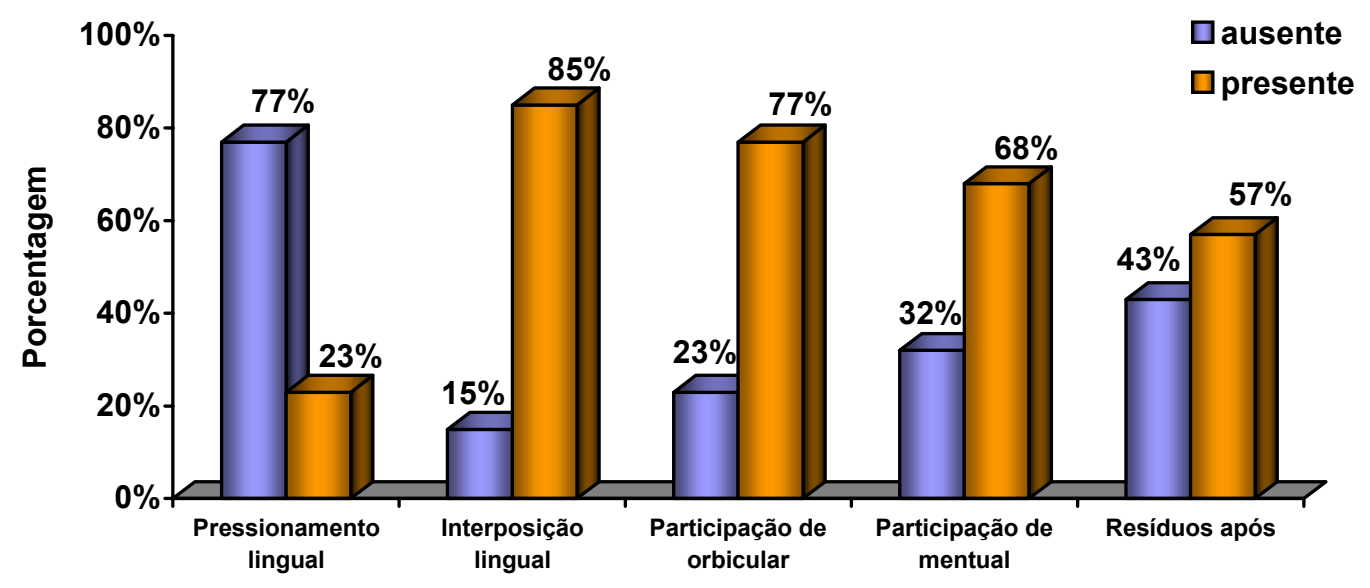


Gráfico 14. Distribuição da amostra segundo a presença ou ausência de alteração da função de deglutição para o grupo II

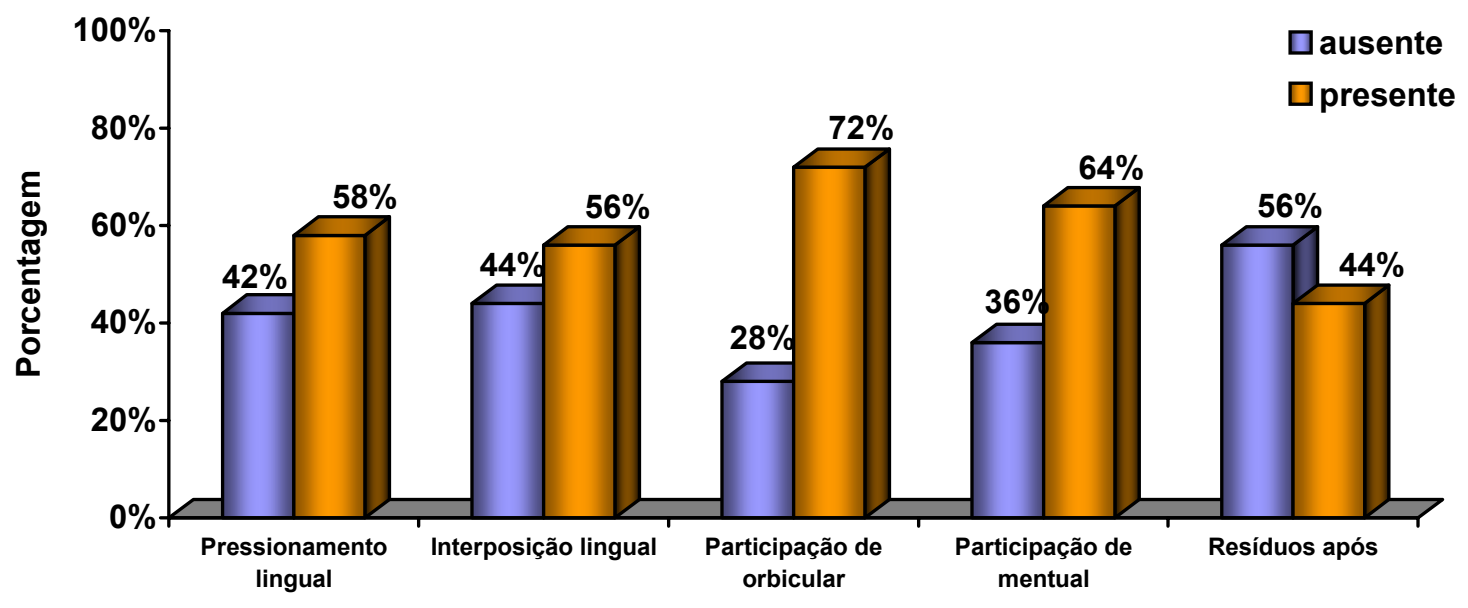

\subsection{Fala}

$\mathrm{Na}$ avaliação da fala, foi investigada se adequada ou alterada quanto aos aspectos fonético, fonológico e tipo articulatório para os grupos I (gráfico 15) e II (gráfico 16). Desses aspectos, o único em que prevaleceu alteração foi o fonético no grupo I, constatado em mais da metade das crianças (62\%). Esse mesmo aspecto no grupo II apresentou ocorrência de alteração em aproximadamente $1 / 3$ um terço da amostra (31\%). Quanto aos tipos de alteração fonética, estes se referem à projeção da língua (17\% para o GI e 11\% para o GII) e desvio da mandíbula (17\% para GI e 14\% para GII), seguidos do ceceio (15\% para GI e 16\% para GII) e troca do ponto articulatório (12\% para GI e 2\% para GII), conforme mostram as tabelas 6 e 7 . Foi verificado, nos dois grupos que algumas crianças apresentaram mais de um tipo de alteração.

Em relação às alterações quanto ao aspecto fonológico (tabelas 6 e 7), estas ocorreram em aproximadamente $1 / 4$ da amostra do grupo I (26\%), tendo sido observado dessonorização (10\%), seguida de redução (6\%), substituição e omissão (4\%), bem como anteriorização e semivocalização (2\%). Já, no grupo II, as alterações ocorreram em poucos casos (11\%), verificando-se semivocalização (11\%), substituição e redução (5\%), bem como anteriorização, posteriorização e dessonorização (2\%). Para os dois grupos pode ser verificado mais de um tipo de simplificação. 
Quanto ao tipo articulatório, houve pouca ocorrência de alteração, tanto no grupo I (28\%) quanto no grupo II (22\%), notando-se o tipo articulatório fechado (17\% para GI e $19 \%$ para GII) e impreciso (11\% para GI e $3 \%$ para GII).

Gráfico 15. Distribuição da amostra segundo a fala adequada ou alterada para o grupo I

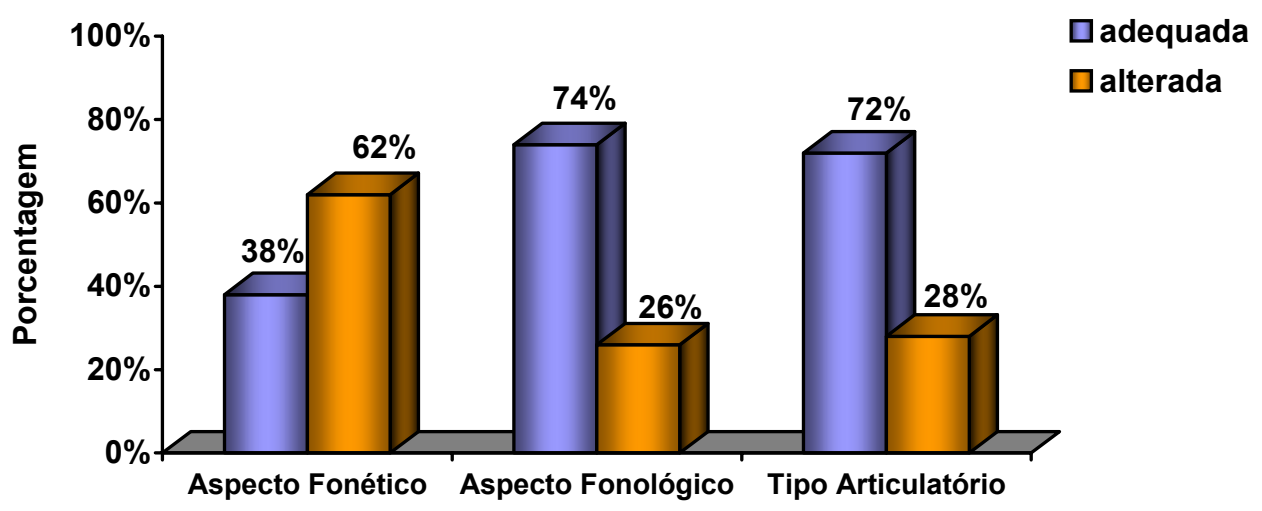

Gráfico 16. Distribuição da amostra segundo a fala adequada ou alterada para o grupo II

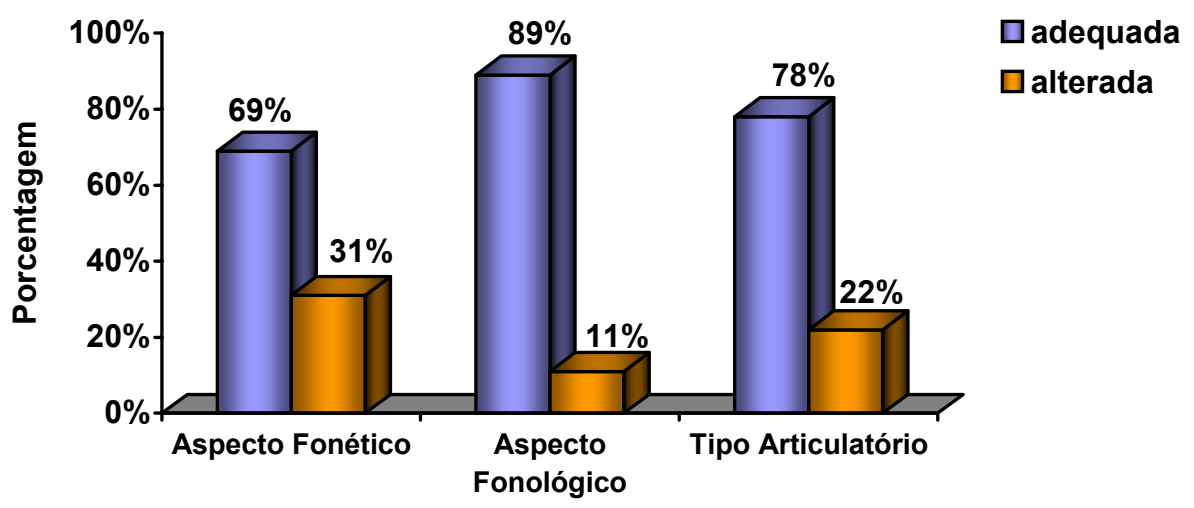


Tabela 6. Tipos de alteração fonética nos grupos I e II

\begin{tabular}{lcc}
\hline \multicolumn{1}{c}{ Tipos de Alteração } & G I & GII \\
\hline Troca do ponto articulatório & $12 \%(n=6)$ & $2 \%(n=1)$ \\
Ceceio & $15 \%(n=7)$ & $16 \%(n=6)$ \\
Projeção de língua & $17 \%(n=8)$ & $11 \%(n=4)$ \\
Desvios & $17 \%(n=8)$ & $14 \%(n=5)$ \\
\hline
\end{tabular}

Tabela 7. Tipos de alteração fonológica nos grupos I e II

\begin{tabular}{lcc}
\hline Tipos de alteração & G I & GII \\
\hline Anteriorização & $2 \%(n=1)$ & $2 \%(n=1)$ \\
Posteriorização & $0 \%(n=0)$ & $2 \%(n=1)$ \\
Dessonorização & $10 \%(n=5)$ & $2 \%(n=1)$ \\
Semivocalização & $2 \%(n=1)$ & $11 \%(n=4)$ \\
Redução & $6 \%(n=3)$ & $5 \%(n=2)$ \\
Substituição do grupo & $4 \%(n=2)$ & $5 \%(n=2)$ \\
Omissões & $4 \%(n=2)$ & $0 \%(n=0)$ \\
\end{tabular}

\subsection{Voz}

$\mathrm{Na}$ avaliação vocal foram analisadas as medidas do tempo máximo fonatório (TMF) na emissão das vogais, bem como das fricativas /s/ e /z/ para calcular-se a relação s/z. Em cada emissão das vogais foram tomadas três medidas para cada criança, tendo sido calculada a média desses valores, e, a partir dessas médias, foi analisado se as mesmas encontravam-se acima, abaixo ou no esperado para as idades em cada emissão, tendo sido observado predomínio de crianças com médias esperadas para a idade, em ambos os grupos (gráficos 17 e 18). 
Gráfico 17. Distribuição da amostra de acordo com o TMF para a emissão das vogais no grupo I

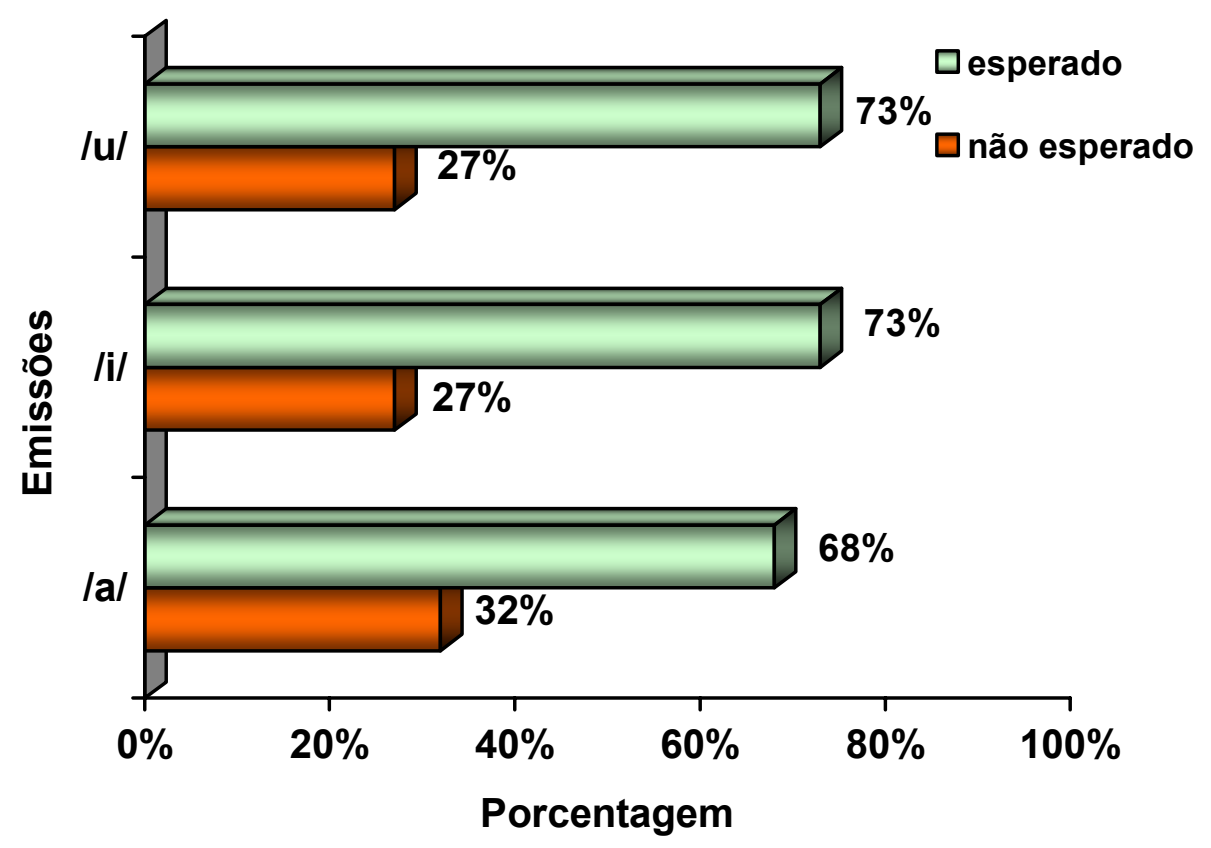

Gráfico 18. Distribuição da amostra de acordo com o TMF para a emissão das vogais no grupo II

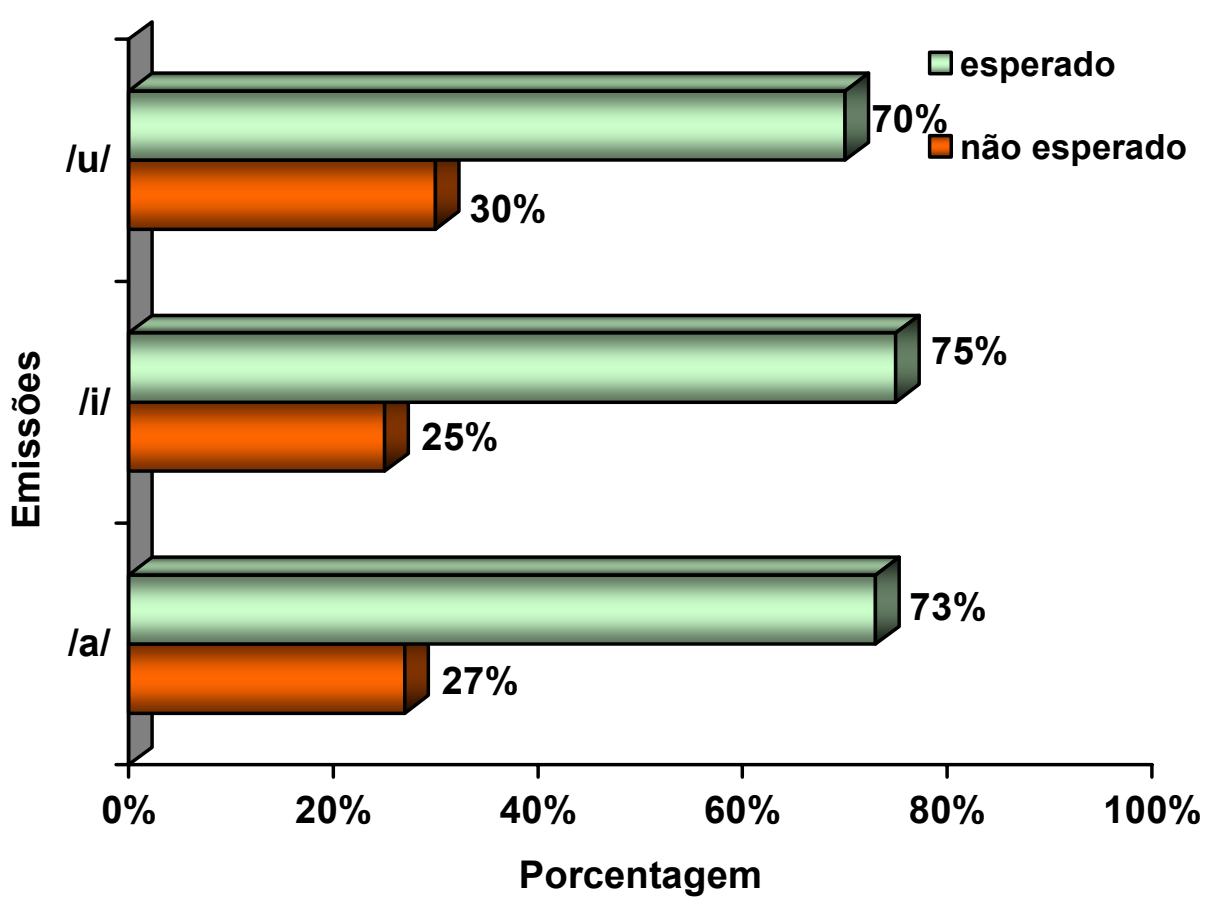


Posteriormente, foi calculada uma média geral de cada grupo em cada emissão, verificando-se valores ao redor de 9 segundos para o grupo I e de 12 segundos para o grupo II (tabelas 8 e 9).

Tabela 8. Valores mínimos, máximos, média e desvio padrão dos TMF, em segundos, para as vogais, bem como da relação s/z no grupo I

\begin{tabular}{lccc}
\hline & la/ & li/ & lul \\
\hline Valor mínimo & 3 & 2,6 & 3 \\
Valor máximo & 20 & 19 & 18,3 \\
Média \pm Desvio Padrão & $9,58 \pm 4,07$ & $9,85 \pm 3,72$ & $9,85 \pm 0,25$ \\
\hline
\end{tabular}

Tabela 9. Valores mínimos, máximos, média e desvio padrão dos TMF, em segundos, para as vogais, bem como da relação s/z do grupo II

\begin{tabular}{lccc}
\hline & la/ & lil & lul \\
\hline Valor mínimo & 6,6 & 5,6 & 4 \\
Valor máximo & 18,3 & 20,6 & 16,6 \\
Média \pm Desvio Padrão & $12,15 \pm 3,25$ & $12,44 \pm 3,21$ & $11,19 \pm 0,35$ \\
\hline
\end{tabular}

No que se refere à relação s/z, esta foi calculada individualmente para cada criança da amostra, e analisado se o valor encontrava-se dentro dos padrões de normalidade (gráfico 19). Foi observado que metade das crianças, em ambos os grupos, apresentavam valores adequados, mas também se observou o valores abaixo do esperado ( $33 \%$ do GI e $28 \%$ do GII) e acima do esperado ( $16 \%$ do Gl e $13 \%$ do GII). 
Gráfico 19. Distribuição da amostra segundo a relação s/z nos grupos I e II

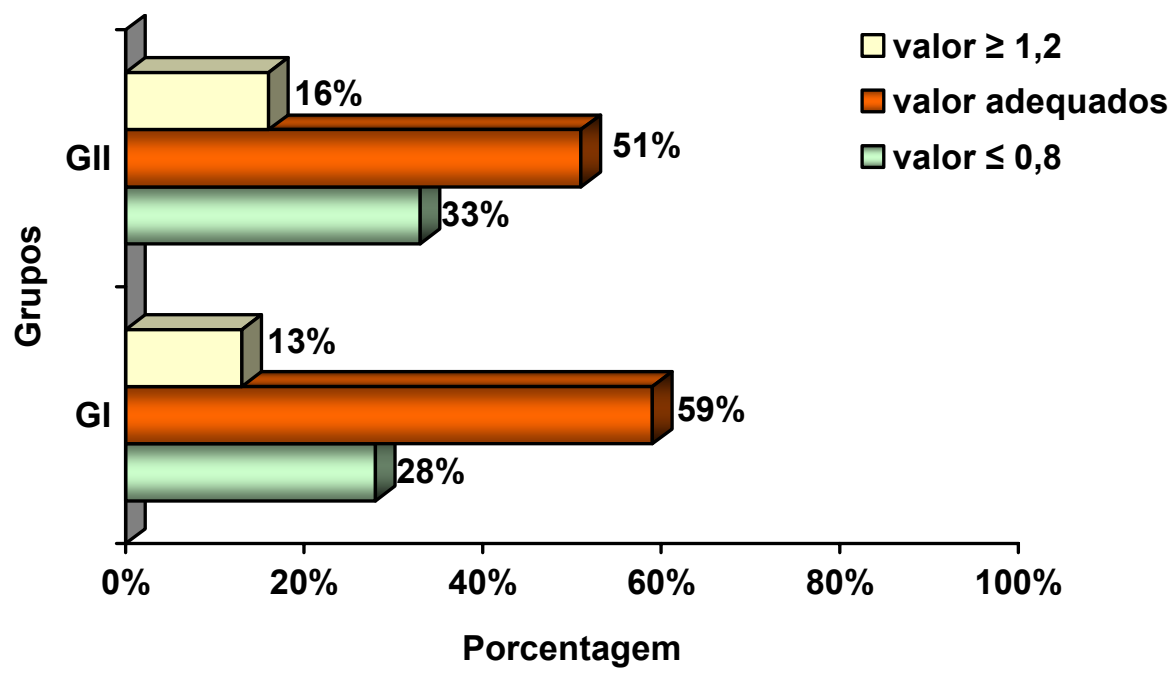

Os resultados da análise perceptivo-auditiva quanto à qualidade vocal, correspondente ao G-grau global da disfonia da escala GRBAS; ao sistema de ressonância, bem como da coordenação pneumofonoarticulatória (CPFA), encontram-se apresentados nos gráficos 20 e 21, respectivamente para os grupos I e II. Nos dois grupos estudados, prevaleceu adequação desses parâmetros, com pouca ocorrência de alteração, sendo similar entre os grupos quanto à ressonância ( $9 \%$ para GI e $6 \%$ para GII) e CPFA (11\% para GI e 14\% para GII). Em relação à qualidade vocal, apesar da ocorrência de alteração também ter sido baixa, esta foi um pouco maior comparado aos outros parâmetros avaliados ( $32 \%$ no GI e $22 \%$ no GII), verificando-se que no grupo I há maior ocorrência de alteração que o grupo II.

Gráfico 20. Distribuição da amostra segundo ao aspecto adequado ou alterado da voz para o grupo I

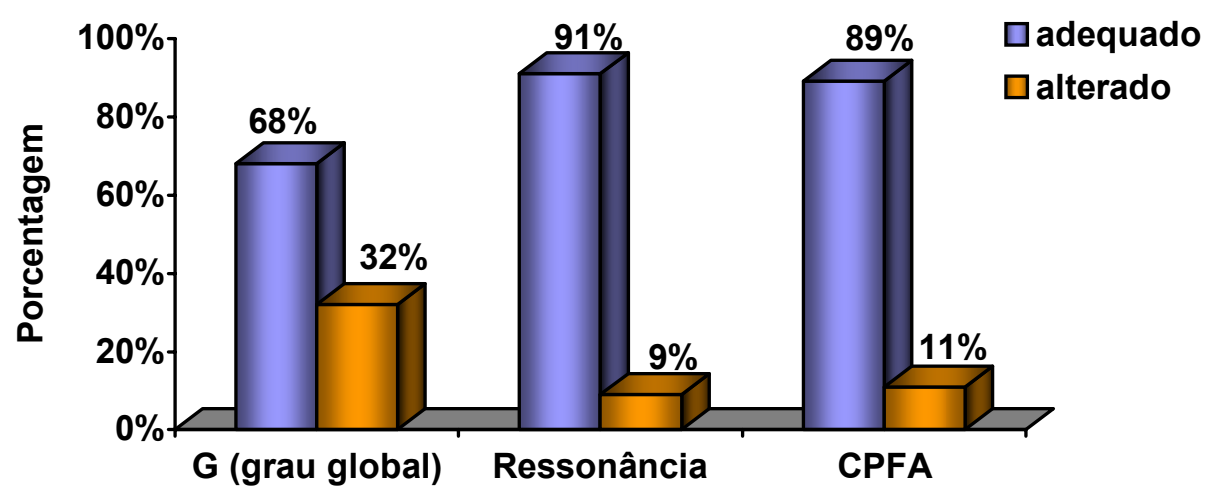


Gráfico 21. Distribuição da amostra segundo ao aspecto adequado ou alterado da voz para o grupo I

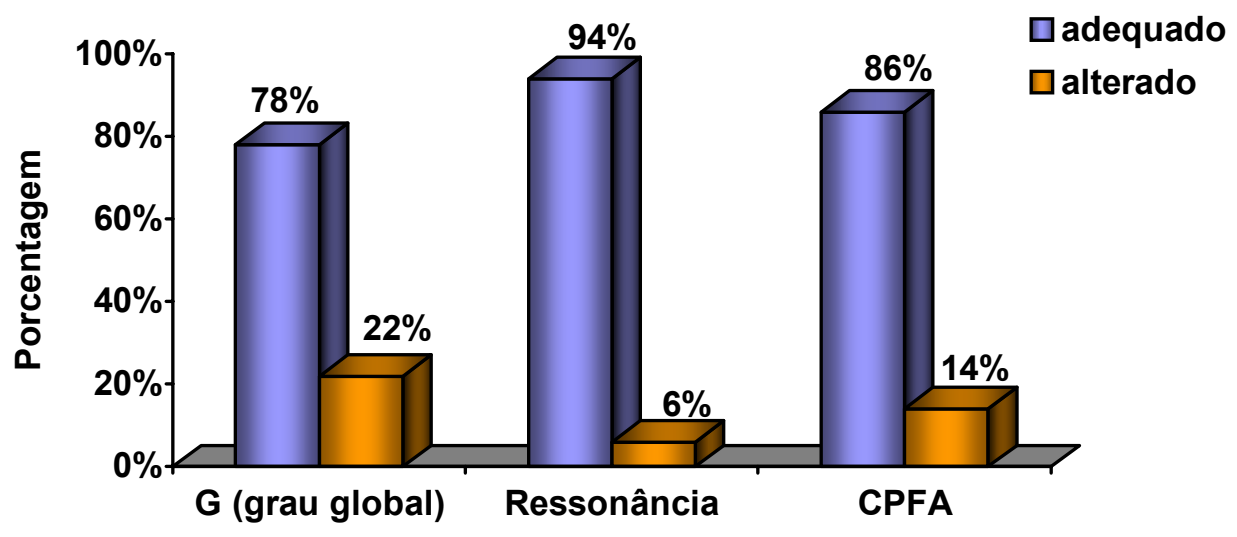


4 Discussão 



\section{Discussão}

A caracterização dos aspectos miofuncionais orofaciais e vocais inserese na Fonoaudiologia, mais especificamente, na área de Motricidade Orofacial, dentro das práticas de promoção de saúde. Atendendo ao primeiro nível de prevenção (LEAVELL; CLARK, 1976), é traçado um perfil da população para conhecer suas necessidades e realidade, permitindo propor ações para sanar ou minimizar as dificuldades e/ou alterações encontradas na população.

Neste trabalho, foram estudadas crianças do município de Monte Negro no estado de Rondônia, onde a Universidade de São Paulo implantou a unidade 5 do Instituto de Ciências Biomédicas (ICB-5), sendo desenvolvidas atividades de extensão e pesquisa junto àquela população. A Faculdade de Odontologia de Bauru, envolvendo o departamento de Ortodontia, Odontopediatria e Saúde Coletiva, juntamente com o departamento de Fonoaudiologia, vem realizando expedições para esse local, visando o desenvolvimento do projeto: "Melhoria das Condições de Saúde Bucal e Fonoaudiológica da população de Monte Negro".

Assim sendo, esta pesquisa insere-se nesse grande projeto da Faculdade de Odontologia de Bauru, com o propósito de identificar a necessidade de ação fonoaudiológica na área de Motricidade Orofacial, pois para iniciar um trabalho nessa área, fez-se necessário inicialmente levantar o perfil da população para posteriormente propor as ações necessárias.

Uma vez que muitas das alterações encontradas no campo da Motricidade Orofacial têm origem durante a fase de desenvolvimento craniofacial (KÖHLER, 2000, DOUGLAS, 2002, PROFFIT, 2002), esta primeira pesquisa priorizou estudar crianças entre 6 e 11 anos de idade. Especialmente nesta fase, a função e a morfologia encontram-se intimamente relacionadas para favorecer a saúde e o equilíbrio do sistema estomatognático (LINDEN, 1990, PONTES, et al.1999, BIANCHINI, 2001, FELÍCIO, 2004, FARIA, 2005). A amostra foi selecionada aleatoriamente e as crianças separadas em dois grupos de acordo com a faixa etária ( $\mathrm{Gl}$ e GII), sendo o grupo I relacionado à faixa etária de 6 a 8 anos e o grupo II à faixa de 9 a 11 anos. A separação da amostra foi necessária, tendo em vista o período de transição dos dentes (LINDEN, 1990, SOUZA-FREITAS, 1991, NEVES, 2003, CANÇADO, 2003), 
pois neste período ocorrem mudanças na cavidade oral relacionadas ao crescimento ósseo e dentário (MOYER, 1991, PROFFIT, 2002, PONTES, et al., 1999), ocorrendo adaptações funcionais, a fim de alcançar um estado de equilíbrio funcional e estrutural (LINDEN, 1990, ENLOW, 1998).

Para atingir o objetivo proposto nesta pesquisa, a caracterização dos aspectos miofuncionais orofaciais e vocais foi realizada por meio da avaliação fonoaudiológica convencional, analisando-se os aspectos estruturais como o tipo facial e a relação dentária. Esses aspectos precisam ser considerados na avaliação, uma vez que a condição funcional do sistema estomatognático está diretamente relacionada à condição estrutural (LINDEN, 1990, PONTES, et al., 1999, MARCHESAN, 1999, KÖHLER, 2000, BIANCHINI, 2001, JORGE, et al., 2002, PROFFIT, 2002, DOUGLAS, 2002, BISHARA, et al., 2006, FELÍCIO, 2004, SANTOS et al., 2006).

Foram avaliados, também, os aspectos musculares como o estado de contração durante o repouso e mobilidade e motricidade, além dos aspectos funcionais como a postura dos lábios e da língua durante o repouso, bem como das funções de respiração, mastigação, deglutição, fala e voz.

Sabe-se que o sistema estomatognático trabalha em equilíbrio para a realização das funções desempenhadas por este (GRABER, 1974, MOYERS, 1991, JOSELL, 1995, GARRETO, 2001, DOUGLAS, 2002, PROFFIT, 2002). Assim, diante de qualquer alteração no sistema, todas as funções podem estar afetadas (LAINE, 1992, HALE, KELLUM, BISHOP, 1998, GOMES, 1999, KRAKAUER, 2001, CATTONI, 2004, AMATÉIA, et al., 2004, WHITAKER, 2005) e, portanto, há necessidade de serem avaliadas, a fim de se compreender os ajustes funcionais realizados (JUNQUEIRA, 2004, MARCHESAN, 1998, BIANCHINI, 2001, GARRETO, 2001, VIEIRA; IÓRIO; MOTTA, 2002, ASSÊNCIO-FERREIRA, 2003, FREITAS; GREGIO; PEREIRA, 2004).

Analisando-se os resultados obtidos nesse estudo, verificou-se em relação ao tipo facial, maior ocorrência do tipo mesofacial para ambos os grupos (74\% para GI e 58\% para GII) e menor ocorrência do tipo dolicofacial (26\% para GI e 42\% para GII), não sendo observado o tipo braquifacial.

O tipo mesofacial apresenta proporção entre os terços da face e boa distribuição dos espaços funcionais, com acomodação da musculatura, não sendo necessárias adaptações funcionais e, o tipo dolicofacial apresenta o 
terço inferior da face aumentada com musculatura débil e estirada (TAY, 1994, CAPELOZZA, 1995, SUGUINO, 1996, VIAZIS, 1996, BIANCHINI, 1998, ENLOW, 1998, PROFFIT, 2002). Deste modo, o tipo dolicofacial requer adaptação funcional à condição estrutural, o que não é necessário para o tipo mesofacial. No entanto, para ser mantido equilíbrio do sistema estomatognático, há necessidade também de se considerar outros aspectos, como a condição dentária e neuromuscular.

No que se refere aos achados da relação dentária, verificou-se alteração nesse aspecto tanto no grupo I (60\%) como no grupo II (42\%), sendo a maior ocorrência relacionada à alteração horizontal, em aproximadamente $20 \%$ em ambos os grupos. Nesse tipo de alteração, podem ser encontrados o trespasse horizontal aumentado e a mordida cruzada anterior (LANGLADE, 1995, HENRIKSON; EKBERG; NILNER, 1997, FERREIRA, 2004, BERRETIN-FELIX; JORGE; GENARO, 2004). Em menor ocorrência foi observada alteração vertical anterior, como a mordida aberta anterior e a sobremordida; a alteração transversal, como a mordida cruzada posterior; bem como os tipos combinados de alteração, tanto horizontal quanto vertical e transversal.

Faz-se necessário considerar o tipo de alteração da relação dentária, uma vez que esta determina a adaptação funcional (GUABA, et al., 1998, CORRÊA, 1999, TOMITA; BIJELLA; FRANCO, 2000, WARREN, 2001, YAMASHITA; HATCH; RUCH, 1999, YASHIRO; TAKADA, 1999, MONGUILHOTT, 2003, FREITAS, GREGIO, PEREIRA, 2004, FARIA, 2005), como a interposição anterior da língua durante a fala e deglutição, a postura habitual dos lábios e da língua alteradas, a disfunção mastigatória, a respiração oral, dentre outras (HALE; KELLUM; BISHOP, 1998, JUNQUEIRA, 1992, TESSITORI; CRESPO, 2002, CHENG et al., 2002, FELÍCIO, 2003b).

No estudo de MACIEL; LEITE, 2005, as maiores ocorrências de alteração relacionaram-se ao trespasse horizontal aumentado, mordida aberta anterior e sobremordida, sendo as menores ocorrências de mordida cruzada posterior bilateral e mordida cruzada anterior. Os resultados mostraram associação entre mordida aberta anterior e interposição de língua durante a deglutição, mas não com a articulação da fala. Além disso, as alterações na respiração, na postura habitual da língua, a interposição lingual durante a deglutição, bem como a hiperfunção da muscular mentual na tentativa de 
selamento labial foram observadas, principalmente, para a mordida aberta anterior e prevalecendo para o tipo dolicofacial.

RODRIGUES et al., 2005, pesquisaram a relação entre alterações na relação dentária e a ocorrência de respiração oral, em casos de 7 a 36 anos de idade, que se encontravam em tratamento ortodôntico. Os resultados mostraram que $70 \%$ dos casos apresentavam respiração oral, além de serem verificados outros sinais que refletem a alteração respiratória, como a postura de lábios alterada, palato ogival e estreito, alterações quanto ao estado de contração muscular, bem como na mastigação e deglutição. Apesar da faixa etária deste estudo diferir da amostra do presente trabalho, se considerarmos que o sistema estomatognático busca adaptação funcional para atingir a condição de equilíbrio, esta pode ser encontrada em qualquer faixa de idade. No entanto, uma vez que o desempenho adequado das funções do sistema estomatognático contribui para o crescimento craniofacial (LINDEN, 1990, STEVENSON; ALLAIR, 1991, ANDRADE; GULO, 1993, ENLOW, 1998, KÖHLER, 2000, DOUGLAS, 2002, FELÍCIO, 2003b, PROFFIT, 2002, LIEBERMAN, 2004), se estas ocorrerem nesta fase, o crescimento poderá estar comprometido.

No presente estudo, verificou-se que no grupo I havia maior ocorrência de alteração (60\%) quanto à relação dentária comparado ao grupo II (42\%). Este fato pode ser justificado pela menor faixa etária deste grupo (6 a 8 anos), período em que ocorrem mudanças na cavidade oral devido às trocas dentárias que se iniciam aos 6 anos de idade (COENRAZ, MOORREES, et al., 1965, LINDEN, 1990, SOUZA-FREITAS, 1991, NEVES, 2003, CANÇADO, 2003). Nesta fase, pode ser observada protrusão dos incisivos superiores, com aumento do trespasse horizontal ou inclinação para lingual dos mesmos, além de espaçamento entre os incisivos nos arcos dentários superior e inferior (PONTES, et al., 1999, FIGUEIREDO; PARRA, 2002, ANTONINI, 2004, FARIA, 2005). Com o crescimento das bases ósseas, ocorre aumento na porção posterior da cavidade oral com o aumento do processo alveolar, favorecendo a irrupção dos molares (CORREA, 1999, FIGUEIREDO; PARRA, 2002, FARIA, 2005). Deste modo, a relação dentária nesta fase está mais estável.

Frente à condição estrutural, a musculatura se adaptará para a realização das funções estomatognáticas (MACMULLEN; DULKI, 2000, NEIVA, 
2003, CAYLEY, 2000a, CAYLEY, 2000b, CHENG, 2002). Pode ser observado que mais da metade das crianças avaliadas, de ambos os grupos, apresentaram alteração quanto à postura habitual dos lábios (66\% do GI e 67\% do GII). No entanto, se considerarmos apenas a relação dentária como justificativa para este achado, este pode não ser confirmado, uma vez que ambos os grupos apresentaram tais alterações. Assim outros aspectos também precisam ser considerados. Um deles refere-se ao tipo facial, onde houve maior ocorrência de tipo dolicofacial para o grupo II, o que poderia justificar as alterações na postura dos lábios e da língua (MOTTA, 2002, BORGHI; ROLDÃO, 2003, MACIEL; LEITE, 2005).

Além disso, um outro aspecto a ser considerado é o estado de contração muscular e a mobilidade e motricidade das estruturas, os quais também interferem na posição habitual dos lábios e da língua, bem como no desempenho das funções orofaciais (JUNQUEIRA, 1997; CAMPIOTTO, 1998).

Em relação ao estado de contração muscular, os achados mostraram diminuição desta condição para mais da metade das crianças estudadas, em ambos os grupos, sendo pouco maior a ocorrência para o grupo I, especialmente para bochechas, lábios e língua. Esses achados justificam as alterações quanto à postura habitual dos lábios e língua encontrada para ambos os grupos, uma vez que a postura habitual dessas estruturas depende, em parte, do estado de contração do músculo (DUCAT, 2001, FELÍCIO, 2003a, FELÍCIO, 2004). Por outro lado, nesses casos, para efetuar o selamento labial, pode ocorrer compensação da musculatura mentual, a qual pode apresentar-se com aumentada contração muscular (BIANCHINI, 2001, FELÍCIO, 2003). Pode ser notado que este fato ocorreu para alguns dos casos avaliados, mas não para todos, os quais mantiveram a postura de lábios abertos ou entreabertos, não compensando com a musculatura mentual. Cabe lembrar que o tipo dolicofacial pode também levar ao aumento da contração muscular do mentual, na tentativa de promover o selamento labial, o que foi encontrado no grupo II.

A mobilidade e a motricidade foram avaliadas, verificando-se maior ocorrência de alteração no grupo I que no grupo II no que se refere a lábios e língua. Esse achado pode ser justificado não apenas pelo estado de contração muscular, mas também pelo desenvolvimento das habilidades motoras com a idade (HAGE, 1999/2000, WERTZNER, 2001). Essa alteração na condição 
motora também pode afetar o desempenho de funções como a mastigação, a deglutição e a fala.

Uma importante função do sistema estomatognático refere-se à respiração, devido ao desenvolvimento e manutenção das estruturas orofaciais, pois, uma vez alterada, pode levar a alterações na musculatura orofacial $\mathrm{e}$ prejuízo a outras funções (KRAMER, 1985, ANDRADE; GARCIA, 1998, KRAKAUER, 2000, TOMÉ; MARCHIORI; PIMENTEL, 2000, GARRETO, 2001, DUARTE, 2003, ANDRADE, 2005, BOTTERO; ANSANELLI; MOTTA, 2005, LESSA, et al., 2005). No presente trabalho, pode ser verificado que esta se apresentou alterada quanto ao modo tanto para o grupo I (62\%) quanto para o grupo II (45\%). Uma vez que o grupo I apresenta maior ocorrência de alteração quanto à relação dentária, ao estado de contração muscular e mobilidade e motricidade, bem como na postura habitual de repouso dos lábios e da língua, os achados quanto à alteração respiratória no grupo I podem ser justificados (SCHINESTSCK, 1996, JUNQUEIRA, 1997, SCHIEVANO; RONTANI; BERZIN; 1999, KAWAMURA et al., 2003, DUARTE, 2003). Além disso, há que se considerar, ainda, as condições ambientais da região, que se apresenta com ruas sem pavimentação e também com pouca infra-estrutura no que se refere aos cuidados com a saúde em geral.

A alteração no modo respiratório pode ter vários agentes etiológicos, como alterações morfológicas, estado de contração muscular ou doenças de vias aéreas superiores (rinites, asma ou sinusite), sendo necessária a intervenção multidisciplinar, principalmente do otorrinolaringologista, para definir o diagnóstico e a conduta (HALE; KELLUM; BISHOP, 1998, TOMITA; BIJELLA; FRANCO, 2000). Porém, tanto o município de Monte Negro quanto a região apresentam poucos profissionais atendendo a população, o que torna preocupante o desenvolvimento global da criança.

Quanto ao tipo respiratório, observou-se maior ocorrência de adequação, sendo que o tipo respiratório médio apresentou maior ocorrência, com menor ocorrência o inferior, não havendo crianças com tipo respiratório completo. Esse achado encontra respaldo na literatura (BEHLAU et al., 2001), embora alguns autores (TOBIN et al., 1983a, TOBIN, et al.,1983b, HERSHENSON et al., 1990, PAPASTAMELOS et al., 1995, VERCHAKELEN; DEMEDTS, 1995, RAGNARSDOTTIR; KRISTINSDOTTIR, 2000, MAYER et al., 
2003) não determinem um tipo respiratório predominante para a faixa etária estudada.

Em relação aos resultados obtidos quanto à função mastigatória, esta se apresentou pouco alterada, nos dois grupos, na maioria dos aspectos avaliados (apreensão, postura labial, tipo e tempo mastigatório). O único aspecto em que prevaleceu alteração (GI com 79\% e Gll com 61\%) foi a formação do bolo alimentar, o que pode ser justificado pelas alterações do estado de contração muscular e mobilidade e motricidade encontradas nesta amostra avaliada (MOTTA, 2002, SCHINEIDER; SENGER, 2001). Percebe-se, ainda, que, no que diz respeito à apreensão do alimento, foram identificadas apenas alterações no GI (17\%), caracterizadas por apreensão lateral, o que pode ser explicado, em alguns casos, pelo período de transição dos dentes (troca dos incisivos centrais) e, também, pelo estado de conservação dos mesmos, inadequado em 49\% das crianças (LINDEN, 1990, PONTES et al., 1999).

Quanto ao tipo mastigatório, este pode apresentar-se alterado diante de alterações na relação dentária (CORRUCCNI; HENERSON; KAUL, 1985, LAINE et al., 1992, TAKADA; MIYAWAKI, 1994, TAY, 1994, MANDETTA, 1994, BIANCHINI, 1998, SILVEIRA; GOLDENBERG, 2001, CATTONI, 2004). Além disso, tanto o tipo mastigatório quanto o tempo mastigatório também podem sofrer influência do estado de conservação dos dentes, somado à perda precoce dos dentes da região posterior, o que pode justificar as alterações encontradas nos dois grupos avaliados (LINDEN, 1990, MANDETTA, 1994, MARCHESAN, 2004, FELÍCIO, 2004). A postura de lábios, durante a mastigação, identificada como às vezes aberta em $28 \%$ dos casos, pode ser justificada pela diminuição do estado de contração muscular dos lábios, bem como devido à respiração oral ou oronasal (TOMÉ; MARCHIORI; PIMENTEL, 2000, NETTO, 2003, DUARTE, 2003, TORO, 2006). Ainda em relação à mastigação, um aspecto a ser considerado refere-se ao tipo de dieta (TOMÉ; MARCHIORI; PIMENTEL, 2000, LIEBERMAM, 2004), que contribui para o desenvolvimento da atividade do músculo masseter, tendo sido observado nas crianças avaliadas, pouca ocorrência de diminuição do estado de contração muscular, justificada pelo tipo de dieta, a qual contem todos os tipos de consistência alimentar. 
No que se refere à deglutição, os dois grupos mostraram grande ocorrência de alteração, sendo esta maior para o grupo I, caracterizada pela participação excessiva da musculatura orbicular e mentual, presença de resíduos após a deglutição, bem como de interposição anterior da língua, além de pressionamento lingual. Estes resultados concordam com os achados quanto à relação dentária, ao estado de contração muscular, a postura habitual dos lábios e da língua, a mobilidade e motricidade, além da respiração e mastigação, uma vez que o sistema estomatognático trabalha em sincronia e, diante de uma função alterada, outras funções também estarão alteradas ou adaptadas à condição estrutural (KRAMER, 1985, BROWN, 1996, TOMÉ et al., 1997, PENG, et al., 2003, KIKYO; SAITO; ISHIKAWA, 1999, KHINDA; GREWL, 1999, GRANVILLE-GARCIA et al., 2000, FUKUMITSU; OHNO; OHNO, 2003, NETTO, 2003, BERTOLINI et al., 2003, KAMAMURA, 2003, CATTONI, 2004, PENG, 2004, FUJIKI, 2004, FRASER, 2006).

As alterações na fala, analisadas quanto aos aspectos fonéticos, foram presentes nos dois grupos, sendo em maior ocorrência no grupo I, destacandose a projeção da língua e os desvios mandibulares. Os resultados quanto à troca do ponto articulatório e projeção de língua podem estar relacionados às alterações nas relações dentárias observadas, visto que o grupo I encontra-se em fase de troca dentária, principalmente, na região anterior (JOSELL, 1995, PEREIRA; SILVA; CECHELLA, 1998, HALLE; KELLUM; BISHOP, 1998, MARCHESAN, 2004).

Os desvios mandibulares também podem ser justificados tanto pelas alterações nas relações dentárias como pelos achados de mobilidade e motricidade mandibular, onde foram observados desvios de trajetória e ruídos na articulação temporomandibular durante a avaliação (BIANCHINI, 2001, FELÍCIO, 2004). Além disso, também foi observado ceceio anterior nos dois grupos, com ocorrência similar entre os mesmos, discordando dos achados de PEREIRA et al., 2003, que referem que a ocorrência deste diminui com a idade. No entanto, esse autor não atribuiu a presença do ceceio apenas à relação dentária, mas também a outros aspectos, como a presença de hábitos orais e alteração respiratória, destacando a importância do estado de contração muscular, o que está de acordo com os achados do presente estudo. Outros autores como PENTEADO; ALMEIDA; LEITE, 1995, PEREIRA; SILVA; 
CECHELLA, 1998, TOME et al.,1998, KHINDA; GREWAL, 1999; SANTOS et al., 2000, FELícIO et al., 2003b, FRIAS et al., 2004, corroboram os estudos de PEREIRA et al., 2003 e aos achados do presente estudo.

No que se refere ao tipo articulatório durante a fala, também investigado neste trabalho, este mostrou-se adequado para a maioria das crianças. No entanto, algumas das crianças apresentaram articulação mais fechada e outras articulação pouco imprecisa. Este achado pode ser justificado pela situação de avaliação em que se encontravam as crianças, criando uma situação diferente da habitual e que pode gerar constrangimento, levando a esse padrão articulatório. Em relação à imprecisão articulatório, esta pode ser atribuída às alterações encontradas quanto ao estado de contração muscular, bem como quanto à mobilidade e motricidade dos lábios e da língua, o que encontrava-se alterado para a maioria das crianças avaliadas.

Outras alterações da fala, como a presença de simplificações fonológicas, também foram encontradas nos dois grupos, porém com ocorrência menor quando comparadas às alterações fonéticas. Comparando-se os dois grupos, as simplificações, embora de ocorrência baixa, foram maiores para o grupo I, apesar de não serem mais esperadas para essas faixas de idade estudadas no presente trabalho (ACOSTA, 2003, LAMPRECHT et al., 2004).

WERTZNER, 2001, refere-se à idade de 7 anos, como fase final para a estabilização de sons mais complexos, como arquifonemas e grupos consonantais, mas tal fato não justifica os tipos de alterações fonológicas encontradas em maior ocorrência no grupo I, sendo estas a dessonorização $(10 \%)$, a redução $(6 \%)$ e omissão (4\%), e, para o grupo II, maior ocorrência de semivocalizações $(11 \%)$, seguido de redução $(5 \%)$ e substituição do grupo consonantal $(5 \%)$, lembrando, ainda, que uma mesma criança poderia apresentar mais de um tipo de simplificação. Essas simplificações podem ocorrer devido à imaturidade articulatória, perceptual e do sistema nervoso (INGRAN, 1976). A aquisição do inventário fonético e das regras fonológicas ocorre de forma gradativa, (YAVAS, 1991, STOEL-GRAMMON; DUNN;1995, ELBERT; GIERUT, 1991; PORTER; HODSON, 2001) onde ocorrem processos de simplificações durante a aquisição da fala até que se organizem as regras fonológicas (DINNSEN; BARLOW, 1998, NOBRE;DE-VITTO, 2005). 
Para os dois grupos, de acordo com as idades seria esperado estabilidade do sistema fonológico, favorecendo a comunicação, o convívio social e o bom rendimento escolar. (WERTZNER, 2001, MOTA, 2001, LAMPRECHT et al., 2004, WERTZNER, 2004, GIERT, 2006), bem como a habilidade de análise, síntese, rima e aliteração, desenvolvendo a consciência fonológica e o código escrito (ADMS et al., 2006).

Quanto à voz, verificou-se, em relação ao tempo máximo fonatório para as três vogais estudadas que, a maioria das crianças de ambos os grupos, apresentaram valores esperados para a idade, encontrando-se ao redor de 9 segundos para o grupo I e 12 segundos para o grupos II (FINNEGAN, 1985; ROCKENBACH; FEIJÓ, 2000). No entanto, observou-se a ocorrência de valores abaixo do esperado para ambos os grupos, que podem ser justificados, em parte, pelos achados quanto ao tipo respiratório, que se apresentou superior em pouco menos da metade das crianças, onde ocorre participação excessiva dos músculos acessórios da respiração, resultando em tensão excessiva da faringe e suprimento impróprio do ar (BEHLAU et al., 2001, ZEMLIN, 2002, LE HUCHE; ALLALI, 2005).

Resultados semelhantes foram observados para a relação s/z em ambos os grupos, onde a maioria das crianças apresentou essa relação próxima à 1 segundo (GAMBOA, 1995; BEHLAU et al., 2001). Foram encontrados, para os dois grupos, valores abaixo de 0,8 segundos, indicando hiperconstrição das pregas vocais à fonação e, em menor ocorrência, valores acima de 1,2 segundos, indicando falta de coaptação das pregas vocais durante a fonação (GAMBOA, 1995; BEHLAU et al., 2001).

Em relação à qualidade vocal, à ressonância e à coordenação pneumofonoarticulatória, pode ser verificado que em ambos os grupos, a maioria das crianças apresentou adequação para esses aspectos. A qualidade vocal (G - grau global de disfonia) (HIRANO, 1981) apresentou maior índice de alteração, variando de $32 \%$ para o Grupo I a $22 \%$ no Grupo II. Esses achados corroboram com o estudo de SIMÕES et al., 2002, que investigou a ocorrência de alteração vocal em crianças de uma creche, obtendo como resultado 23,6\% de alteração vocal. As alterações apresentadas podem estar relacionadas às alterações de outras funções como deglutição, mastigação e, principalmente, a respiração, encontradas em nossos achados e que podem fazer parte dos 
quadros de disfonia (FREITAS; WECKX; PONTES, 2000, VIOLA, 2001, PAES, 2005).

Com a finalização deste trabalho, pode-se verificar que os objetivos foram alcançados, uma vez que a amostra foi caracterizada quanto aos aspectos miofuncionais orofaciais e vocais. Esse fato possibilita a elaboração de programas visando à prevenção e à reabilitação dos aspectos avaliados. Portanto, esse estudo mostrou-se fundamental para a continuidade das ações propostas pela Faculdade de Odontologia de Bauru relacionada à área de Motricidade Orofacial.

Um aspecto de merece ser considerado, refere-se ao período de transição dentária em se encontravam as crianças avaliadas, sendo necessário o acompanhamento das mesmas, a fim de se verificar os fatores que podem interferir no crescimento e desenvolvimento craniofacial da criança.

A partir dos resultados observa-se a importância de projetos que atuem principalmente quanto às funções de respiração e deglutição, com orientações aos pais e professores, bem como às próprias crianças, formações de pequenos grupos para terapias intensivas e acompanhamento periódico dos casos, bem como o auxilio de outros profissionais, visando à atuação multidisciplinar. 
5 Conchusão 



\section{Conclusão}

A partir das avaliações e análises realizadas verificaram-se as seguintes características miofuncionais orofaciais e vocais nas crianças:

- Tipo mesofacial com pouca ocorrência de tipo dolicofacial;

- Relação dentária alterada para aproximadamente metade da amostra, com maior ocorrência de alteração horizontal;

- Postura habitual alterada para lábios e língua para a maioria das crianças;

- Estado de contração muscular, para a maioria da amostra, diminuído quanto a bochechas, lábios e língua, e para menos da metade da amostra, diminuído para masseter e aumentado para mentual em mais da metade das crianças mais velhas, e em 1/3 das crianças mais novas;

- Mobilidade e Motricidade alterada para lábios e língua em metade das crianças mais novas, com menor ocorrência para as crianças mais velhas; alterada também quanto à mandíbula para menos da metade das crianças avaliadas e preservada para o véu palatino;

- Respiração alterada quanto ao modo para aproximadamente metade da amostra estudada, com maior ocorrência para as crianças mais novas, e também alterada quanto ao tipo em menos da metade da amostra, sendo maior a ocorrência para as crianças mais novas;

- Mastigação alterada quanto à formação do bolo alimentar para a maioria das crianças avaliadas, além de pouca ocorrência de alteração quanto à apreensão do alimento, postura labial, tipo e tempo mastigatórios;

- Deglutição alterada para a maioria dos casos, caracterizada por interposição lingual, participação de musculatura orbicular e de mentual e presença de resíduos após a deglutição, e pressionamento lingual apenas nas crianças mais velhas;

- Fala alterada quanto ao aspecto fonético para mais da metade das crianças mais novas e para menos da metade das crianças mais velhas, pouca alteração quanto ao aspecto fonológico e tipo articulatório, sendo pouco maior para as crianças mais novas;

- Voz com tempo máximo fonatório, relação s/z e qualidade vocal alterados para menos da metade da amostra; com pouca ocorrência de alteração quanto à ressonância e coordenação pneumofonoarticulatória. 


\section{-}


Aneros 



\section{Anexo 1 - Aprovação do Comitê de Ética em Pesquisa da Faculdade de Odontologia de Bauru/USP}

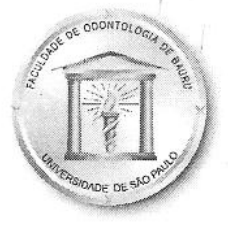

Processo $n^{\circ} 121 / 2005$

\section{Universidade de São Paulo}

Faculdade de Odontologia de Bauru

Al. Dr. Octávio Pinheiro Brisolla, 9-75 - Bauru-SP - CEP 17012-901 - C.P. 73

PABX (0XX14)3235-8000 - FAX (0XX14)3223-4679

Comitê de Ética em Pesquisa (3235-8356)

Bauru, 02 de dezembro de 2005.

Senhora Professora,

Informamos que após o envio da documentação solicitada referente ao projeto de pesquisa encaminhado a este Comitê de Ética em Pesquisa "Perfil das funções estomatognáticas das crianças do município de Monte Negro/RO" de autoria de Luciana Biral Mendes Merighi que será desenvolvido sob sua orientação, foi novamente analisado e considerado APROVADO por este Comitê em reunião realizada no dia $\mathbf{3 0}$ de novembro de 2005.

Informamos ainda, que após o envio do trabalho concluído, este Comitê enviará o parecer final, que será utilizado para publicação do trabalho.

Atenciosamente,

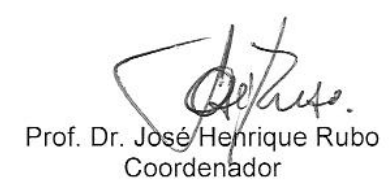

IIm ${ }^{\mathrm{a}} \mathrm{Sr}^{\mathrm{a}} \mathrm{Prof}^{\mathrm{a}} \mathrm{Dr}^{\mathrm{a}}$ Kátia Flores Genaro

DD. Docente do Departamento de Fonoaudiologia 


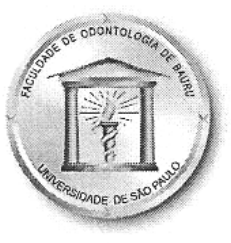

\section{Universidade de São Paulo \\ Faculdade de Odontologia de Bauru}

Al. Dr. Octávio Pinheiro Brisolla, 9-75 - Bauru-SP - Brasil - CEP 17012-901 - C.P. 73 PABX (0XX14)3235-8000 - FAX (0XX14)3223-4679

Comitê de Ética em Pesquisa (3235-8356)

Of.nO CEP/16 2006/FOB

Proc. CEP no 121/2005

Bauru, 20 de outubro de 2006.

Senhora Professora,

Informamos que após análise por este Comitê de Ética em Pesquisa em Seres Humanos, a alteração do título do projeto de pesquisa "Perfil das funções estomatognáticas das crianças do município de Monte Negro/RO" de autoria de Luciana Biral Mendes Merighi, sob sua orientação, para "Características miofuncionais orofaciais e vocais das crianças do município de Monte Negro/RO" foi aprovado considerando que não houve modificação em sua metodologia.

Lembramos que após o envio do trabalho concluído, este Comitê enviará o parecer final, que será utilizado para a publicação do trabalho.

Atenciosamente,

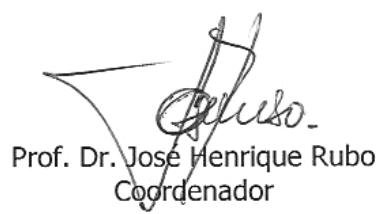

Profa Dra Kátia Flores Genaro

Docente do Departamento de Fonoaudiologia 


\title{
Anexo 2 - Carta de Autorização
}
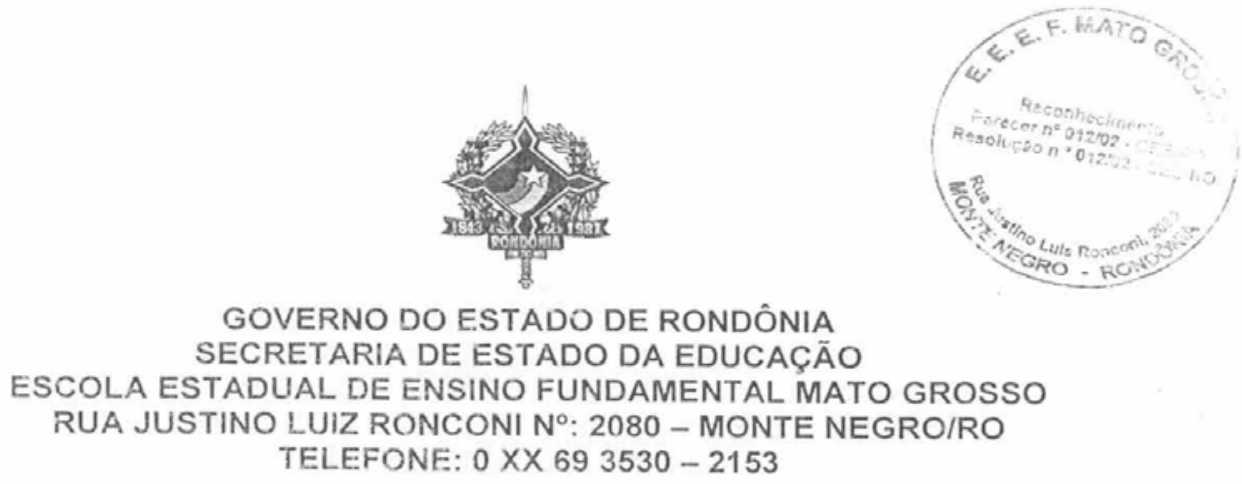

\section{Carta de Autorização}

\begin{abstract}
Em resposta ao pedide da
pesquisadora em mestrado Luciana Biral Mendes Merighi a E.E.E.F. Mato Grosso esta autorizando a referida aluna do departamento de fonoaudiologia da Faculdade de Odontologia de Bauru/ USP, a fazer a pesquisa com o titulo Perfil das funções estogmáticas das crianças do município de Monte Negro RO. Sugerimos que seja realizado no mês de fevereiro de 2006, em vês de janeiro por ser período de recesso escolar. A mesma poderá ser realizada em horário oposto as aulas.
\end{abstract}

Sendo o que temos pari o momento, elevamos votos de estima e

consaturiation

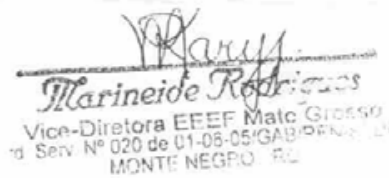

Monte Negro-RO, 20 de outubro de 2005. 


\title{
Anexo 3 - Carta de informação ao paciente
}

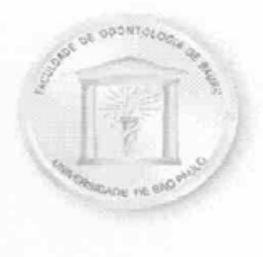

\author{
Universidade de São Paulo \\ Faculdade de Odontologia de Bauru \\ Al. Dr. Octávio Pinheiro Brisolla, 9-75 - Bauru-SP-CEP 17012-101 - C.P. 73 \\ PABX (0XX14)235-8000 - FAX (0XX14)223-4679 \\ Departamento de Fonoaudiologia \\ e-mail: dep-fono a fob usp.br - Fone: (0XX14)235-8232
}

\section{CARTA DE INFORMAÇÃO AO PARTICIPANTE}

Título do Projeto: "Perfil das funções estomatognáticas das crianças de Monte Negro/RO'

Autora: Luciana Biral Mendes Merighi,

Orientadora: Profa ${ }^{a}$ Dr. ${ }^{a}$ Katia Flores Genaro

Este trabalho avaliará crianças do município de Monte Negro/RO, a fim de identificar possíveis alteração nas funções de respiração, mastigação, deglutição, fala e voz. Para essas avaliações será feito observação da realização destas funções, sendo que a mastigação, a deglutição e a fala serão filmadas e, para a análise da voz, será realizado a gravação. Os participantes irão comer alimentos como bolacha e pão, assim como tomarão água.

Essas avaliações não são invasivos, não causarão dano à saúde física e mental e seus riscos são próximos de zero. O participante terá a garantia de receber resposta a perguntas ou esclarecimento a qualquer dúvida acerca dos procedimentos, riscos, benefícios e outros assuntos relacionados com a pesquisa, e - mesmo terá a liberdade de retirar seu consentimento a qualquer momento ou deixar de participar do estudo, sem a necessidade de expor as razões. Toda informação obtida decorrente desse projeto de pesquisa será submetida aos regulamentos da FOB/USP referentes ao sigilo da informação. $O$ nome do participante será preservado nos resultados ou informações que forem utilizados para fins de publicação cientifica.

Caso haja dúvidas ou reclamações poderão ser feitas diretamente ao Comitê de Ética e Pesquisa em Seres Humanos, da Faculdade de Odontologia de Bauru/USP (AI. Dr. Octávio Pinheiro Brisolla, 9-75, sala no prédio da Biblioteca), ou pelo telefone (14) 3235-8356. 


\title{
Anexo 4 - Termo de Consentimento Livre e Esclarecido
}

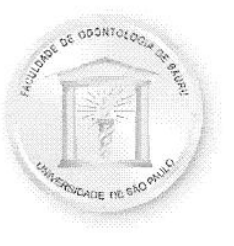

\author{
Universidade de São Paulo \\ Faculdade de Odontologia de Bauru \\ Al. Dr. Octávio Pinheiro Brisolla, 9-75 - Bauru-SP - CEP 17012-101 - C.P. 73 \\ PABX (0XX14)235-8000 - FAX (0XX14)223-4679 \\ Departamento de Fonoaudiologia \\ e-mail: dep-fono a fob.usp.br - Fone: (0XX14)235-8232
}

TERMO DE CONSENTIMENTO LIVRE E ESCLARECIDO

Pelo presente instrumento que atende às exigências legais, o Sr.(a)

portador da cédula de identidade após leitura

minuciosa da CARTA DE INFORMAÇÃO AO PACIENTE, devidamente explicada pelos profissionais em seus mínimos detalhes, ciente dos serviços e procedimentos aos quais será submetido, não restando quaisquer dúvidas a respeito do lido e explicado, firma seu CONSENTIMENTO LIVRE E ESCLARECIDO concordando em participar da pesquisa proposta.

Fica claro que o paciente ou seu representante legal, pode a qualquer momento retirar seu CONSENTIMENTO LIVRE E ESCLARECIDO e deixar de participar desta pesquisa e ciente de que todas as informações prestadas tornaram-se confidenciais e guardiadas por força de sigilo profissional.

Por estarem de acordo assinam o presente termo.

Monte Negro/RO, de de 
Referências Bübliográficas 



\section{REFERÊNCIAS BIBLIOGRÁFICAS}

1. ACOSTA, V.M.; MORENO, A.; RAMOS, V.; QUINTANA, A.; ESPINO, O. Avaliação do desenvolvimento fonológico. In: ACOSTA, V.M.; MORENO, A.; RAMOS, V.; QUINTANA, A.; ESPINO, O. Avaliação da linguagem: teoria e prática do processo de avaliação do comportamento lingüístico infantil. São Paulo: Santos, 2003. p. 53-70.

2. AMATÉIA, et al. A importância da avaliação postural no paciente com disfunção da articulação temporomandibular. Ac Othop Bras. v.12, n.3 jul/set 2004.

3. ADMS, J. M. et al. Consciência fonológica em crianças pequenas. Porto Alegre. Armed, 2006. p. 215.

4. ANDRADE, C. R. F. de; GULLO, A; Alteração do sistema motor-oral dos bebês como causa das fissuras/rachaduras mamilares. Pediatria, São Paulo, v.15, p. 28-33, 1993.

5. ANDRADE, C. R. F. de; GARCIA, S. F. A influência do tipo de aleitamento no padrão de sucção do bebê. Pró-fono, v. 10, n. 1, p.40-44, mar. 1998.

6. ANDRADE, F. V. et al. Alterações estruturais de órgãos fonoarticulatórios e más oclusões dentárias em respiradores orais de 6 a 10 anos. $\underline{\operatorname{Rev}}$ CEFAC, São Paulo, v.7, n.3, 318-25, jul-set, 2005

7. ANGLE, E. H. Treatment of malocclusion of the teeth. Philadelphia. 7 ed., Philadelphia: White Dental Manufacturing Co, p.628, 1907.

8. ANTONINI, A. et al. Class II malocclusion with maxillary protrusion from the deciduous through the mixed dentition: a longitudinal study. The Angle Orthodontist, v. 75, n. 6, p. 980-86, sep. 2004.

9. BEHLAU, M.et al. Avaliação da voz. In: Voz: o livro do especialista. Rio de Janeiro: Revinter, 2001 col. 1,cap.3, p. 85-176.

10. BERRETIN-FÉLIX, G.; JORGE. T. M; GENARO, K. F. Intervenção fonoaudiológica em pacientes submetidos à cirurgia ortognática. In: FERREIRA, LP; BEFI-LOPES, D. M; LIMONGI, SCO (org). Tratado de fonoaudiologia. São Paulo: Roca, 2004. p. 495-511. 
11. BERTOLINI, M. M. et al. Cephalometric evaluation in children present adapted swallowing during mixed dentition. Int. J. Orofacial Myology. 2003. V. 29, p.29-41

12. BIANCHINI, E.M.G. Mastigação e ATM: avaliação e terapia. In: MARCHESAN I.Q. Fundamentos em fonoaudiologia - aspectos clínicos da motricidade oral. $1^{\text {a }}$ ed. Rio de Janeiro: Guanabara Koogan, 1998. p.37-50.

13. BIANCHINI, E.M.G. Avaliação fonoaudiológica da motricidade oral Distúrbios miofuncionais orofaciais ou situações adaptadas. Dental Press Ortodon. Ortop Facial, Maringá, v. 6, n. 3, p. 73-82, maio/jun. 2001.

14. BISHARA, et al. Changes in the prevalence of nonnutritive sucking patterns in the first 8 years of life. AmJ Orthod Dentofacial Orthop. v. 130, n.1, p. 31-36, July, 2006.

15. BORGBI, L. C. ROLDÃO, F. T. F. MARIOTTO, M. Postura habitual dos lábios mais encontrada em crianças. Rev CEFAC, v.5 .p.227-230, 2003.

16. BOTTERO, E.;ANSANELLI; L. S. C; MOTTA, A. R. Ocorrência de respiração oral em pacientescom doenças periodontais. Rev CEFAC, São Paulo, v.7, n.3, 363-70, jul-set, 2005.

17. BROWN, C. Orofacial Myofunctional Disorders. Pract Periodontics Aesthet Dent, v. 8, n. 7, p. 698, 1996.

18. CAMPIOTTO, A. R. Fonoaudiologia. In: SOUZA, L.C.M. (Org.). Cirurgiaortognática e ortodontia. São Paulo: Ed. Santos, 1998. p. 19-30.

19. CANÇADO, H.R. Estudo comparativo da cronologia de erupção dos dentes permanentes e da calcificação dos segundos molares nas más oclusões de classe I e classe II de Angle. [Dissertação]. Bauru: Faculdade de Odontologia de Bauru; universidade de São Paulo, 2003.

20. CAPELOZZA FILHO, L. Análise facial: fita de vídeo. São Paulo: Funcraf, 1995. 1 fita de vídeo (61:22"), VHS.

21. CASTRO, M. M. de; WERTZNER, H. F. P. Estimulabilidade e tipos de erro de fala. Res Soc Bras Fonoaudiol. V.11,n. 1, 2006, p.1-9

22. CATTONI, D. M. Alterações da mastigação e deglutição. In: Ferreira, LP; Befi-Lopes, DM; LIMONGI, S.C.O (org). Tratado de Fonoaudiologia. São Paulo: Roca, 2004. p. 277-291. 
23. CAYLEY, A. S., et al. Electropalatographic and cephalometric assessment of myofunctional therapy in open bite subjects. Aust. Orthod. J. v.16, n. 1, p. 23-33, mar. 2000a.

24. CAYLEY, A. S., et al. Electropalatographic and cephalometric assessment of tongue function in open bite and non-open bite subjects. Eur. J. Orthod. V.22, n. 5, p. 463-474, oct. 2000b.

25. CHENG, C. F. et al. Dentofacial morphology and tongue function during swallowing. Am J Orthod Dentofacial Orthop 2002;122:491-9.

26. COENRAZ, F. A., MOORREES, et al. - Availble space for the incisoros during dental development. Boston, Massachusetts. Am. J. Orthod., 35:1222, 1965.

27. CORRÊA, M. S. N. P. Odontologia na primeira infância. São Paulo: Santos, 1999. cap. 46 , p. 857-874.

28. CORRUCCINI, R. S.; HENDERSON, A. M.; KAUL, S. S. Bite fosse variation related to occlusal variation in rural and urban Punjabis (North Índia). Arch Oral Biol., New York, v.30, n. 1, p.65-6, 1985.

29. DINNSEN, D. A; BALOW, J.A. On the characterization of chain shift in normal and delayed phonological acquisition. J Child Lang, v. 25, p. 61 94; 1998.

30. DOUGLAS C.R. Tratado de fisiologia aplicada à odontologia. São Paulo: Robe, 2002.

31. DUARTE L.I.M. Respiração e mastigação: estudo comparativo. Rev. Dental Press Ortod Ortop Facial, v. 5, n.4 , p. 79-87, 2003.

32. DUCAT, P. R. et al. Estudo populacional e achados de alterações orofaciais. Rev CEFAC, v3, p.143-148, 2001.

33. ENLOW, D. H.; HANS, M. G. Noções basicas sobre crescimento facial. São Paulo: Ed. Santos, 1998. p. 200-219.

34. ELBERT, M.; GIERUT, J. Handbook of clinical phonology approaches to assessement and treatment. Pro-Ed. Austim. Secund Edition, 1991.

35. FARIA, M. de M. G; Odontologia aplicada a fonoaudiologia. In: BRITO, A. T. B. de O. (org). Livro de Fonoaudiologia. ed. Pulso, 2005. p.63-92.

36. FAW, T. Psicologia do desenvolvimento: infância e adolescência. São Paulo: McGraw-Hill, 1981. 
37. FELÍCIO C.M de. Desenvolvimento normal das funções estomatognáticas. In: FERREIRA, L. P; BEFI-LOPES, D. M; LIMONGI, S. C. O. (org). Tratado de fonoaudiologia. São Paulo: Roca, 2004. p. 195-211.

38. FELÍCIO, C. M. de. et al. Analise da associação entre a sucção, condições miofuncionais orais e fala. Pró-fono. Barueri, v. 15, n. 1,p.31-44, jan./abr. 2003b.

39. FELÍCIO, C. M. Avaliação do sistema estomatognático: síntese de algumas propostas -Parte I, v.4, n.17, p.283-90, 2003ª.

40. FERREIRA, F. V. Ortodontia : diagnóstico e planejamento clínico. São Paulo Editora Artes Médicas, 2004, p.553.

41. FIGUEREDO, M. de C; PARRA, S.L.N. Desenvolvimento da dentição mistaParte3.Disponívelem:<http://www.odontologia.com.br/artigos.asp?id= 122>. Acesso em: 30 ago. de 2006.

42. FINNEGAN, D. E. Maximum phonation time for children whit normal voices. Folia Phoniat. v. 37, 1985, p. 209-215

43. FUJIKI, T. et al. Relationship between maxilliofacial morphology and deglutitive tonge in patients with anterior open bite. Am J Orthod. Dentofacial Orthop. v. 125, n. 2, p. 160-167 feb. 2004.

44. FUKUMITSU, K.; OHNO, F.; OHNO,T.Lip sucking and lip biting in theprimary dentition: two cases treated with a morphological approach combined with lip exercises and habituation. Int. J. Orafacial Myology. v. 29, p. 42-57, nov. 2003.

45. FURKIM, A. M.; BEHLAU, M. S.; WECKX, L. L. M. Avaliaçäo clínica e videofluoroscópica da deglutiçäo em crianças com paralisia cerebral tetraparética espástica. Arq. neuropsiquiatr; v.61, n.3a, p. 611-616, set. 2003.

46. FRASER, C. Tongue thrust and its influence in orthodontics. Int. J. Orthod. Milwaukee. Spring; v.17, n. 1, p. 9-18, 2006.

47. FREITAS, V.S.;GREGÓRIO,F.N.; PEREIRA, F.A.Características mastigatórias em crianças na dentição mista. Rev CEFAC 2003;4:55-58

48. FREITAS, M. R; WECKX, L. L. M; PONTES, P. A. de L. Disfonia na infância. Rev Bras Otorrinolaring. V. 66, ed. 3, 257-265. maio/jun. 2000. 
49. FRIAS, J. S. et al. Relação entre ceceio anterior e crescimento craniofacial e hábitos de sucção não nutritiva em crianças de 3 a 7 anos. Rev CEFAC, São Paulo, v.6, n.2, 177-83, abr-jun, 2004

50. GAMBOA, F. J. et al. S/Z ratio in glottic clouse defects. Acta Otorrinolaring. Esp. v. 46. n. 1, p.45-48, jan-fev. 1995,

51. GARRETTO, A.L. Orofacial myofuncional disorders related to malocclusion. Int. J. Orofacial Myology. v. 27, p 33-43, Nov. 2001.

52. GENARO, k. F. ;YAMASHITA R. P, TRINDADE, I. E. K.Avaliação clínica e instrumental na fissura labiopalatina. In: FERREIRA, L.P; BEFI-LOPES, DM; LIMONGI, S.C.O (org). Tratado de fonoaudiologia. São Paulo: Roca, 2004. p.456-477.

53. GIERUT,J.A. Treatment Efficacy: functional phonologhical disorders in children.Journal of Langague, Speech Hear Res,41(1);85-100,1998.

54. GRABER, T. M. Ortodontia: teoria y pratica. 3 ed. México: Interamenricana, 1974. cap. 6, p.152-176.

55. GRANVILLE-GARCIA, A. F. et al. Fisiologia da deglutição infantil normal. $\underline{J}$ Bras Fonoaudiol, Curitiba, v.1 n.2, p.27-29, jan./mar. 2000.

56. GOMES, R. C. G. Relações entre postura corporal e sistema estomatognático. J Bras de Fonoaudiol. n. 1, 1999.

57. GUABA K. A. et al. Prevalence of malocclusion and oral habits in North Indian rural children. J Indian Soc. Pedon. Prev. Dent. V.16, n.1, p. 26-30, mar. 1998.

58. HAGE, S. R. V. Dispraxias articulatórias:correlações com 0 desenvolvimento da linguagem. In: MARCHESAN I; ZORZI, J.(org). Anuário CEFAC 1999/2000. Revinter. Rio de Janeiro.P. 119-130.

59. HALE, S.T.; KELLUM, G. D.; \& BISHOP, F. W. Prevalence of oral muscle and speech differences in orthodontic patients. Int J of Orofacial Myology. v.14, n.2, p.6-10. 1998.

60. HENRIKSON, T; EKBERG, E. C.; NILNER, M. Simptoms and signs of temporomandibular disorders in girls with normal occlusion and class II malocclusion. Acta Odontol. Scand., Stockholm. v. 55, n. 4, p. 229-35, Aug 1997. 
61. HERSHENSON, M. et al.Changes in the contribution of the rib cage totidal breanthig during infancy. Am. Rev. Respir. Disord. v.141, p. 922-5, apr. 1990.

62. HIRANO, M. Clinical examination of voice. New York: Springer-Verlarg Wien, 1981.

63. INGRAM, D. Phonological disability in children. Edwaud Arnold; London 1976.

64. JORGE, T. M. ET. AL. Hábitos bucais - Interação entre odontologia e fonoaudiologia. J Bras Odontopediatr Odontol Bebê, Curitiba, v.5, n. 26, p. 342-350, 2002.

65. JOSELL, S.D. Habits affecting dental and maxillofacial growth and development. Dent Clin North Am, Philadelphia, v.39, n.4 p.851-860, Oct. 1995

66. JUNQUEIRA, P. S. A investigação da mastigação em indivíduos portadores de classe III de Angle. Pró-fono. Barueri, v. 4, n.2, p.29-31, 1992.

67. JUNQUEIRA P. Avaliação e diagnostico fonoaudiológico em motricidade Oral. In: FERREIRA, L.P; BEFI-LOPES, DM; LIMONGI, S.C.O (org). Tratado de fonoaudiologia. São Paulo: Roca, 2004. p.195-211.

68. JUNQUEIRA, P. S. A postura em repouso dos órgãos fonoarticulatórios frente aos limites anatômicos do paciente na terapia miofuncional. Prófono Revista de Atualização Científica. Barueri, v. 9, n.1, p.59-61, 1997.

69. KAWAMURA, M. et al. A cineradiographic study of deglutitive tongue movement in patients with anterior open bite. Bull Tokyo Dent. Coll., v. 44, n. 3, p. 133-139, Aug, 2003.

70. KHINDA, V.; GREWAL, N. Relationship of tongue-thrust swallowing and anterior open with articulation disorders: a clinical study. J. Indian Soc, Pedod. Prev. Dent. v.17, n. 2, p. 33-39, jun. 1999.

71. KIKYO, T; SAITO, M; ISHIKAWA, M. A study comparing ultrasound images of tongue movements between open bite children and normal children in the early mixed dentition period. J. Med. Dent. Sci. 1999; v. 46, n.3, p.127-37. 
72. KÖHLER N.R.W. Distúrbios miofuncionais: Considerações sobre seus fatores etiológicos e conseqüência sobre o desenvolvimento da face. $\underline{\operatorname{Rev}}$. Dental Press Ortodon Ortop Facial; v.5, n.3, p.66-79, 2000.

73. KRAMER, S. S. Special swallowing problems in children. Abdominal Imaging. 1985; v. 10, n. 3, p. 241-50.

74. KRAKAUER, L. H. Relações entre respiração bucal e alterações posturais em crianças: uma análise descritiva. Ver Dental Press Ortop Facial., Maringá, set/out de 2000.

75. LAINE, M. T. et al. Associations among different orofacial dysfunctions in 6-8 year olds. Arch Oral Biol. v. 37, n. 11, p.895-899, nov. 1992.

76. LANGLADE, M. Diagnóstico Ortodôntico, São Paulo: Santos, 1995.

77. LAMPRECHT, R. R. e cols. Aquisição fonológica do Português: perfil do desenvolvimento e subsídios para a terapia. Artmed, Porto Alegre, 2004.

78. LEAVELL H; CLARK E.G. Medicina preventiva. Editora McGraw-Hill do Brasil; 1976.

79. LÊ HUCHE, F.; ALLALI, A. Voz. Anatomia e fisiologia da voz e da fala. Porto Alegre. Artmed, $3^{\mathrm{a}}$ ed., v.1, 2005.

80. LIEBERMAN, D.E. et al. Effects of food processing on masticatory strain and craniofacial growth in a retrognathic face. J Human Evol 46 (2004) 655-677.

81. LESSA, F. C. R., et al. Influência do padrão respiratório na morfologia craniofacial. Rev. Bras. Otorrinolaringol., mar./abr. 2005, vol.71, no.2, p.156-160.

82. LINDEN F. P. G. VANDER. Crescimento e ortopedia facial. São Paulo; Quintessence, 1990.*

83. MACIEL C.T. V; LEITE I. C. G. Aspectos etiológicos da mordida aberta anterior e suas implicações nas funções orofaciais. Pró-fono. Barueri, v. 17, n.3,p.293-302, set/dec. 2005.

84. MACMULLEN, N.J. DULSKI, L. A.Factors related to sucking ability in healthy newborns. J Obstet Gynecol Neonatal Nurs.; v.29, n.4, p.390-6, Jul-Aug. 2000MANDETTA S. Causas da mastigação unilateral e importância do ajuste oclusão das guias laterais na sua correção. Rev Paul Odont; v. 16, n. 1, p. 18-20, 1994. 
85. MARCHESAN, I.Q. Deglutição - Diagnóstico e possibilidades terapêuticas. In: MARCHESAN I.Q. Fundamentos em fonoaudiologia aspectos clínicos da motricidade oral. $2^{\mathrm{a}}$ ed. Rio de Janeiro: Guanabara Koogan, 1999. p.51-58.

86. MARCHESAN, I.Q. Deglutição - Normalidade. In: FURQUIM, A. M; SANTINI, C. S. Disfagias Orofaríngeas. Carapicuíba; Pró-fono, cap.1, p.4 $-18,1999$.

87. MARCHESAN, I Q. Alterações de fala de origem músculoesquelética. In: FERREIRA, L.P; BEFI-LOPES, D.M; LIMONGI, S.C.O (org). Tratado de fonoaudiologia. São Paulo: Roca, p.292-303. 2004.

88. MAYER, O. H. et al.Respiratory inductance plethysmography in healthy 3to 5- year-old children. Chest, v. 124, n.5, p.1813-1818, nov. 2003

89. MELO, E. C. M. et al. Disfonia infantil: aspectos epidemiológicos. Rev Bras Otorrinolaring. V. 67, n.6, 804-7. nov/dez. 2001.

90. MELO, T. M; ARRAIS, R. D.; GENARO, K.F, Duração da mastigação de alimentos com diferentes consistências. Rev Soc Bras Fonoaudiol. v.11, n.3, p.170-4, jul/se.t 2006.

91. MONGUILHOTT L. M. J; FRAZZON J. S; CHEREM V. B. Habitos de sucção: como e quando tratar na ótica da ortodontia $X$ fonoaudiologia. Rev. Dent. Press. Ortodon. Ortop. Maxilar. V. 8, n.1 p.95-104, jan/fev. 2003.

92. MOTA, H. B. Terapia fonoaudiológica para os desvios fonológicos. Rio de Janeiro. Revinter.2001. 109p.

93. MOTTA, A. R. A mastigação no período Intertransicional da dentição mista. Rev. Dental. Press. Ortodon. Ortop. Facial. V. 7, n.5, p.77-86, set/out. 2002.

94. MOYERS, R. E. Ortodontia. Guanabara Koogan, 4. ${ }^{a}$ ed., Rio de Janeiro, 1991.

95. NEIVA, F. C. B., et al. Desmame precoce: implicações para o desenvolvimento motor-oral. Jornal de Pediatria, v. 79, n.1, 2003.

96. NETTO, C. R. S; Deglutição na criança, no adulto e no idoso. Fundamentos para Odontologia e fonoaudiologia. São Paulo: Lovise; 2003 
97. NEVES, L.S. Estudos comparativos da maturação e erupção dos dentes permanentes em jovens com padrões de crescimento vertical e horizontal. [Dissertação]. Bauru: Faculdade de Odontologia de Bauru, Universidade de São Paulo, 2003.

98. NOBRE, T. L; DE-VITTO, L. P. M. Desvios fonológicos: considerações bibliográficas relevantes sobre avaliação e intervenção fonológica. J.Bras.de Fonoaudiol. 2005; 5(23):424-30.

99. OLIVEIRA, M.I. Avaliação da voz; reflexões sobre condutas, com enfoques à voz profissional. In: FERREIRA, LP; BEFI-LOPES, D. M; LIMONGI, SCO (org). Tratado de fonoaudiologia. São Paulo: Roca, 2004. p. 11-24.

100. PAES, C; VIEIRA, J; LEONEL, T; CUNHA, D. A. de. O impacto da respiração oral no comportamento vocal. J Bras. de Fonoaudiol. 2005; v.5, n.23, p. 417-23.

101. PAPASTAMELOS, C. et a. Developmental changes in chest wall compliance in inancy early childhood. Am Appl Physiol. 1995.

102. PENTEADO, R. Z.; ALMEIDA, V. F.; LEITE, Ė. F. D. Saúde bucal em préescolares: estudo fonoaudiológico e odontológico. Pró-Fono Revista de Atualização Ciêntífica, v. 4, n.2, p.21-29, set. 1995.

103. PENG, C. I. et al. Differential diagnosis between infantile and mature swallowing with ultrasonography. Eur. J. Orthod. v. 25, n. 5, p. 451456.oct; 2003.

104. PENG, C. I. et al. Comparison of tongue functions between mature and tongue-thrust swallowing -an ultrasound investigation. American Journal of Orthodontics and Dentofacial Orthopedics. v. 125, n. 5, p. 562-570. 2004.

105. PEREIRA, L. F.; SILVA, A. M. T.; CECHELLA, C. Ocorrência de hábitos orais viciosos e distúrbios fonoarticulatórios em indivíduos portadores de deglutição atípica. Pró-fono. Barueri, v. 10, n.1, p.56-60, 1998.

106. PEREIRA, M. M. B. et al. Investigação da ocorrência e caracterização de distorções do [s] em crianças de 3 a 10 anos. Sociedade Brasileira de Fonoaudiologia, n. 1, p. 10-17, jun. 2003. 
107. PONTES, A. C. L. R. et al. Reflexão sobre a doença periodontal e sua relação com a atuação fonoaudiológica na presença de hábitos bucais. Pró-fono. Barueri, v. 11, n. 2, p.80-84, 1999.

108. PORTER, J. H, HODSON, B. W. Collaboration to obtain phonological acquisition data for local schools. Language Speech and Hearing Services in schools. v.32, p. 1665-171, july, 2001.

109. PROFFIT, W. R. Ortodontia Contemporânea. 3 ed. São Paulo: Pancast, 2002.

110. RAGNARSDOTTIR, M.; KRISTINSDOTTIR, E. k. k. Breathing movements and breathing patterns among hearly men and woman 20-69 years of age. Respiration, v.73, p. 48-54, aug. 2006.

111. ROCKENBACH S. P; FEIJÓ A. V. Estudo do tempo máximo de fonação em crianças de 6 a 10 anos de idade. Pró-Fono v.12, n. 2, p. 81-5, 2000.

112. RODRIGUES, H. O. S. N.et al. Ocorrência de respiração oral e alterações miofuncionais orofaciais em sujeitos em tratamento ortodôntico. $\underline{\operatorname{Rev}}$ CEFAC, São Paulo, v.7, n.3, 356-62, jul-set, 2005

113. SANTOS, L. K. et al. Ocorrência de alteraçõs de fala, do sistema sensóriomotor oral e de hábitos orais em crianças pré-escolares da $1^{\circ}$ grau. Pró-fono. Carapicuíba, v. 12, n. 2, p.93-101, set. 2004.

114. SCHIEVANO, R. M. P; RONTANI, F.; BÉRZIN, F. Influence of myofunctional therapy on the perioral muscles. Clinical and electromyographic evaluations. J. Oral Rehab. v. 26, n. 7, p. 564 - july 1999

115. SCHINESTSK, P. A. A relação entre a maloclusão dentária, a respiração bucal e as deformidades esqueléticas, J. Bras. Ortod. Ortop. Maxilar, v.1,n:4, p.45-55, 1996.

116. SCHNEIDER, G.; SENGER, B. Coffe beans as a natural test food for the evaluation of the masticatory efficiency. J Oral Reabil, v.28, p. 342-8, 2001.

117. SHEPPARD, J. J; MYSAK, E. D. Ontogeny of Infantile Oral Reflexes and Emerging Chewing. 1984; v. 55; n. 3, p.831-43.

118. SIMÕES, et al. Alteração vocal em crianças que frequentam creche. ProFono. Revista de Atualização Científica. v. 14, n.3, p. 343-350, set-dez. 2002 
119. SILVEIRA, L. D. B. R. da GOLDENBERG, M. Hábitos e preferências alimentares de crianças com três a cinco anos de idade. Rev CEFAC. v, 3. n. 37, p. 44, 2001.

120. SOUZA FREITAS, J. A.; LOPES, E. S.; DAMANTE, J. H. Cronologia de mineralização e de erupção dos entes permanentes. Rev. Odont. Bras v. 48, n. 2, p. 2-7, mar./abr. 1991.

121. STEVENSON, R. D; ALLAIRE, J.H. The development of normal feeding and swallowing. Pediatr. Clin. North. Am. 1991, v.38, p.1439-53.

122. STOEL-GAMMON, C., DUNN C. NORMAL And disorderd phonology in children. Austin: Pro-Ed, 1985.

123. SuguinO, R. et al. Análise Facial. Rev. Dental Press Ortod. Ortop. Maxilar. V.1, n.1, p. 86-107.set/out. 1996.

124. TAKADA, T.; MIYAWAKI, S.; TATSUTA, M. The effects of food consistency on jaw movement and posterior temporalis and inferior orbicularis oris muscle activities during chewing in children. Arch Oral Biol. v. 39, n. 9, p. 793-805. sep. 1994.

125. TAY, D. K. L. Physiognomy in the classification of individuals whth a lateral preference in mastication. J Orofacial Pain, v. 8, n. 1, 1994, p. 61-72.

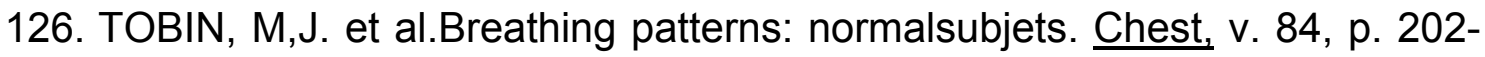
$205,1983 a$

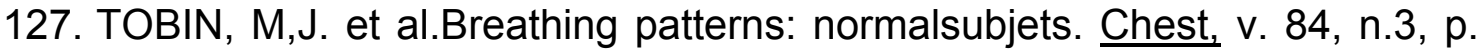
286-294, 1983b

128. TOMÉ, M. C. et al. Estudo da ocorrência de alterações da deglutição e da oclusão dentária em crianças com queixa de fala errado. . Pró-fono. Barueri, v. 10, n. 1, p.61-65, 1998.

129. TOMÉ, M.C. MARCHIORI, S. C., PIMENTEL, R. Mastigação Implicação na dieta alimentar do respirador bucal. J Brás Fonoaudiol, v. 3, P.60-5. 2000.

130. TOMITA, N. E.; BIJELLA, V. T.; FRANCO, L. Relação entre hábitos bucais e má oclusão em pré-escolares. Rev. Saúde Publica. V. 34, n. 3, p. 299303. 2000.

131. TORO, A. et al. Masticatory performance in children and adolescents with Class I and II malocclusions. Eur J Orthod. v. 28, n. 2, p.112-119, 2006. 
132. VERCHAKELEN, J. A.; DEMEDTS, M. G. Normal thorocoabdominal motions: influence of sex, age, posture and breath size. Am J Respir Crit Care Med. V.151, p. 399-405, 1995.

133. VIAZIS, A. D. Avaliação do tecido mole. Atlas de Ortodontia. Princípios e aplicações clínicas. P. 49, 1996.

134. VIEIRA, R. A.;IÓRIO, A. P.; ASSENCIO-FERREIRA, V. J. características mastigatórias em crianças de 2 a 5 anos. Rev CEFAC 2003;5:59-62

135. VIOLA, I. C. Estratégias terapêuticas na disfonia infantil. In: Congresso Brasileiro de Fonoaudiologia, 9., 2001, Guarapari. Anais...São Paulo: Sociedade Brasileira de fonoaudiologia. p. 67.

136. WERTZNER, H. F. P. Classificação dos distúrbios fonológicos por meio de duas medidas de análise: porcentagens de consoantes corretas(PCC) e índice de ocorrência dos processos (PDI). Pró-fono Revista de atualização Científica, v. 13 n. 1, p. 90-97, mar. 2001.

137. WERTZNER, H. F. P. Fonologia: Desenvolvimento e alterações. In: FERREIRA, L.P; BEFI-LOPES, DM; LIMONGI, S. C. O (org). Tratado de fonoaudiologia. São Paulo: Roca, 2004. p.772-786.

138. WHITAKER, M. E. Função Mastigatória: Proposta de protocolo de avaliação clínica. [Dissertação]. Bauru: Hospital de Reabilitação de Anomalias Craniofaciais da Universidade de São Paulo. 2005.

139. YASHIRO, K; TAKADA, K. Tongue muscle activity after orthodontic treatment of anterior open bite: A case report. Am J Orthod Dentofactial Orthop 1999;115:660-6.

140. YAMASHITA, S.; HATCH, J. P.; RUGH, J. D. Does chewing performance depend upon a specific masticatory pattern? J. Oral Rehabil. v.26, n. 7,p. 547. July. 1999.

141. YAVAS, M; Hernandorena, C. L. M.; LAMPERCHT, R.R. Avaliação fonológica da criança :reeducação e terapia. Porto Alegre. Artes Medicas, 1991. 148p.

142. ZEMLIN, W. R. Princípios de anatomia e fisiologia em fonoaudiologia. $4^{a}$ ed. Porto Alegre: Artes Medicas, 2002. p. 624. 
Abstract 



\section{Abstract}

The accomplishment of the orofacial functions is fundamental to promote craniofacial's balance and development, when accomplished correctly.

Thus, myofunctional disturbs can intervene negative with the craniofacial development, also reflecting in the psychosocial development of the child.

The objective of this work was to characterize the orofacial and vocal myofunctional aspects of the children of the city of Monte Negro/RO. Respecting the ethical aspects, 83 school children were evaluated and divided in groups in accordance with the age: GI (47 children between 6 and 8 years) and GII (36 children between 9 and 11 years).

We verified in the orofacial myofunctional evaluation the following aspects: face type and dental habits; habitual position of lip and language; state of muscular contraction of masseter, cheek, lip, language and mentual; mobility/motricity of lips, tong, jaw and palatal veil; beyond breathing, chew, deglutition, speech and voice. We used movie recordings and recording in MD for the collection of the data.

Mesofacial and dolichofacial types were observed; alteration in the dental relation, with bigger occurrence in the $\mathrm{GI}$, characterized mainly for horizontal alteration; great occurrence of alteration in the lip and tong position, as well as in the state of muscular contraction, being diminished for cheek, lip and language and increased to masseter and mentual; difficulty in the lip and tong mobility, and little alteration in the mandible mobility; more than the half of the $\mathrm{Gl}$ showed modified respiratory way and less of the half in the GII, with little alteration in the respiratory type in the two groups; little occurrence of alteration in the chew, except in the formation of the alimentary bolus, observed in more than the half of the sample; great occurrence of alteration in the deglutition, but a little bigger in the $\mathrm{Gl}$; phonetic alteration of speech was also present in more than the half of the $\mathrm{Gl}$ and less in the GII, with little speech alteration in the articulator type; e, little occurrence of vocal alterations.

Thus, in view of the occurrence of myofunctional alterations in the studied sample, the promotion of action for the adequacy of the modified functions becomes necessary for the good development of the children of the city of Monte Negro/RO.

Key Words: breathing, chewing, deglutition, speech, voice. 